\title{
Numerical Investigation of Novel Dynamic Installed Fish Anchors in Clay and Calcareous Silt
}

\section{Y. H. Kim ${ }^{1}$, M. S. Hossain ${ }^{2}$ and K. Chang ${ }^{3}$}

${ }^{1}$ Corresponding Author, Research Associate (PhD), Centre for Offshore Foundation Systems (COFS), The University of Western Australia, 35 Stirling highway, Crawley, WA 6009, Tel: +61 86488 4316, Fax: +61 86488 1044, Email: youngho.kim@uwa.edu.au

${ }^{2}$ Senior Research Fellow (BEng, MEng, PhD, MIEAust), Centre for Offshore Foundation Systems (COFS), The University of Western Australia, Tel: +61 (0)8 6488 7358, Fax: +61 (0)8 6488 1044, Email: muhammad.hossain@uwa.edu.au

${ }^{3}$ Research Student, Centre for Offshore Foundation Systems (COFS), The University of Western Australia, 35 Stirling highway, Crawley, WA 6009, Tel: +61 (0)8 6488 7358, Fax: +61 (0)8 6488 1044, Email: kuntan.chang@research.uwa.edu.au

- $\quad$ Number of Words: 5362 (text only)

- $\quad$ Number of Tables: 02

- $\quad$ Number of Figures: 16 


\title{
Numerical Investigation of Novel Dynamic Installed Fish Anchors in Clay and Calcareous Silt
}

\begin{abstract}
This paper reports the results from three-dimensional dynamic finite element analysis undertaken to provide insight into the behaviour of a novel dynamically installed anchor (DIA), termed as fish DIA, during dynamic installation and monotonic pullout in nonhomogeneous clay and calcareous silt. The fish DIA has an elliptic-shaped shaft, which reduces hydrodynamic drag resistance. The shaft is shaped to be thicker near the head to lower the mass centroid, and increase its diving potential with a specialised padeye position. A series of large deformation finite element analyses have been carried out considering the relevant range of parameters in terms of soil undrained shear strength; impact velocity, padeye offset ratio and pullout angle. Considering the difference in soil undrained shear strength, and DIA dimensions and mass; overall anchor tip embedment depths of the fish DIA lied in the range of that of the OMNI-Max DIA. The tracked anchor trajectory confirmed that, compared to the OMNI-Max DIA, the fish DIA dove deeper and earlier for a wide range of padeye offset ratio. These are more critical and beneficial for calcareous silt where the achieved embedment depths are generally lower compared to those in clay.
\end{abstract}

Keywords: anchors; clays; silts; numerical modelling; offshore engineering 


\section{INTRODUCTION}

Dynamically installed anchors (DIAs) are the most recent generation of anchoring systems for mooring floating facilities for deep water oil and gas developments. During installation, the DIA is released from a specified height above the seabed. This allows the DIA to gain velocity as it falls freely through the water column before impacting the seafloor and embedding into the sediments.

In recent years, broadly two DIA geometries have evolved. The torpedo DIAs are rocketshaped, typically consist of a long shaft, with the loading point (or padeye) attached at the top, and may feature up to 4 relatively small fins at the trailing edge (Brandão et al., 2006; Lieng et al., 2010). The OMNI-Max DIAs feature three large fins with intermittent discontinuity to accommodate an arm that transfers the loading point nearer to the head of the anchor (Zimmerman et al., 2009; Nie and Shelton, 2011). More than 1,500 DIAs (until 2009) have been used for anchoring deep water flowlines and facilities at the Campos Basin, offshore Brazil and at the Gjøa field in the North Sea, off the Western coast of Norway and the Gulf of Mexico in water depths ranging from 200 m to 1,400 m (Brandão et al., 2006; Lieng et al., 2010; Shelton et al., 2011).

The motivation of this study has emanated directly from the need identified by the offshore industry in an attempt to extend the application of DIAs in calcareous sediments e.g. in the Australia's North-West Shelf. Most previous field trials and installations were limited in clayey sediments, and no attempt was taken to install DIAs in calcareous soils. Centrifuge model tests have been carried out on existing DIAs (e.g. torpedo anchor) at the University of Western Australia (Hossain et al., 2014, 2015). The anchor embedment in calcareous silt, with shear strength $0 \sim 2.5 \mathrm{kPa}$ at the mudline and gradient $2.9 \sim 3.3 \mathrm{kPa} / \mathrm{m}$, was significantly lower (1 1.4 $\mathrm{L}_{\mathrm{A}}$; where $\mathrm{L}_{\mathrm{A}}$ is the anchor length) than that in clay $\left(1.5 \sim 3 \mathrm{~L}_{\mathrm{A}}\right)$ under similar or even 
higher impact velocity. This was due to: (i) the stronger strain rate dependency in calcareous silt compared to clay (Boukpeti and White, 2011) and (ii) the dilative behaviour of calcareous silt compared to contractive behaviour of clay (Mao and Fahey, 2003; Miao and Airey, 2013).

Generally, the deeper embedment depths of DIAs guarantee higher pullout capacity due to the increase in shear strength (Richardson et al., 2009; O’Loughlin et al., 2009, 2013; Hossain et al., 2014, 2015; Kim and Hossain, 2016). In addition, several studies have demonstrated that the lowered padeye position may allow the anchor to embed further (through diving) during pullout (Tian et al., 2014; Liu et al., 2016b; Zhao et al., 2016; Kim and Hossain, 2017). The diving behaviour would distinctly increase anchor's pullout capacity and eliminate the risk of catastrophic failure (Zimmeman et al., 2011). It would be especially beneficial for calcareous sediments in which the embedment depth is relatively shallow and holding capacity is usually inadequate.

A new DIA shape, termed as fish DIA due to the geometric similarity, combines the advantages of streamline body for the deeper penetration depth and lowered padeye position for the higher pullout capacity. This is illustrated in Figure 1 with comparisons of existing DIAs, and dimensions are given in Table 1. The fish DIA comprises a main elliptic coneshaped shaft. Every cross section of the shaft is an ellipse and the widest part (A-A' plane; see Figure 1c) is in the middle with a constant major and minor axis ratio of 2.36. During the free fall through the water column, the elliptic-shaped shaft reduces hydrodynamic drag resistance, with the drag coefficient $\left(C_{d}\right)$ being 0.04 (Young et al., 2010) compared to 0.22 0.42 for a torpedo DIA's cylindrical shaft (Richardson, 2008). To stabilise the trajectory during free fall in water, balancing the mass, two sets of four body and tail fins are attached to the middle and the tail of the shaft, respectively. The shaft is shaped to be thicker near the anchor head to lower the mass centroid to increase the diving potential upon pullout. The padeye is fitted 
perpendicularly to the wider part of the shaft (y-z plane; see Figure 1c), so that the maximum resistance area can be mobilised under operational loading.

The main aim of this study is to investigate the performance of the fish DIA during installation and pullout through three-dimensional (3D) dynamic LDFE analyses. If the fish DIA leads eventually greater capacity, compared to torpedo and OMNI-Max DIAs, ensuring better diving potential, it can be recommended to be applicable the fields with calcareous sediments. A series of integrated dynamic installation-monotonic pullout analyses have been carried out accounting for strain softening and strain rate dependency of the undrained shear strength. An extensive parametric investigation was undertaken, varying the relevant range of various parameters related to the impact velocity, pullout inclination angle and padeye offset ratio. Improved rational approaches are then proposed for assessing the embedment depth and diving potential of DIAs.

\section{NUMERICAL ANALYSIS}

3D LDFE analyses were carried out using the Coupled Eulerian-Lagrangian (CEL) approach in the commercial finite element package ABAQUS/Explicit (Version 6.12, Dassault Systèmes, 2012). Extensive background information about installation and pullout modelling of DIAs can be found in Kim et al. (2015a) and Kim and Hossain (2015, 2017), which are not repeated here.

Considering the symmetry of the problem, only a half anchor and soil domain were modelled. The lateral extension of the soil domain were $55 D_{p}$ from the centre of the anchor $\left(D_{p}\right.$ is the anchor frontal projected area $\left(\mathrm{A}_{\mathrm{p}}\right)$ equivalent diameter) on the pullout loading direction and $17 \mathrm{D}_{\mathrm{p}}$ on the opposite respectively. A typical mesh is shown in Figure 2. The Eulerian mesh 
comprised 8-noded linear brick elements (termed EC3D8R in ABAQUS) with reduced integration.

A very fine soil mesh was necessary to capture the anchor-soil contact accurately. Therefore, mesh convergence studies were first performed to ensure that the mesh was sufficiently fine to give accurate results. As shown in Figure 3a, four different mesh densities were considered for a fish anchor installation ('very fine mesh zone' in Figure 2) under an identical impact velocity of $v_{i}=19 \mathrm{~m} / \mathrm{s}$. The numerical results based on mesh 1 and mesh 2, with minimum element size $\left(h_{\min }\right) 0.15 t_{F}$ and $0.18 t_{F}$ respectively (where $t_{F}$ is the fin thickness), are essentially identical, indicating that mesh convergence was achieved with the density of mesh $2\left(\mathrm{~h}_{\min }=0.18 \mathrm{t}_{\mathrm{f}}\right)$. For the continuous inclined pullout simulation, again four different mesh densities in the dragging area ('fine mesh zone' in Figure 2) were tested at the same pullout angle $\left(\theta_{a}=30^{\circ}\right)$ and padeye offset ratio $(\eta=0.4)$. As shown in Figure 3b, mesh convergence was achieved with a slightly larger element size of $0.5 t_{f}$ (mesh 2) compared to vertical installation. As such, for subsequent analyses, the typical minimum soil element size along the trajectory of the anchor was selected as $0.18 \mathrm{t}_{\mathrm{F}}$ for vertical installation (very fine mesh zone) and $0.5 t_{\mathrm{F}}$ for inclined pullout (fine mesh zone). These minimum element sizes are consistent with previous preliminary convergence studies on the OMNI-Max DIA (Kim and Hossain, 2017). To reduce computational time, a large size of element with aspect ratio $\approx 6 \sim$ 200 (see Figure 2) was used at the boundary of the soil domain. It was ensured through trial analyses that this element size in the far-field has no influence on the simulation results, and the extensions of the soil domain are sufficiently large to avoid boundary effect. The anchor was simplified as a rigid body and assumed to remain vertical during the penetration process, with no tilt. 
The simulation was fully integrated taking into account the disturbed soil conditions during the installation of the anchor for the pullout stage. The dynamic installation and pullout of DIAs are completed under undrained conditions. The soil was therefore modelled as an elasto-perfectly plastic material obeying a Tresca yield criterion, but extending to capture strain-rate and strain-softening effects using the Einav-Randolph (Einav and Randolph, 2005) models according to

$$
\begin{aligned}
& \mathrm{s}_{\mathrm{u}}=\left[\left(\frac{\operatorname{Max}\left(\mid \&_{\mathrm{ref}}\right)}{\&_{\mathrm{ref}}}\right)^{\beta}\right]\left[\delta_{\mathrm{rem}}+\left(1-\delta_{\text {rem }}\right) \mathrm{e}^{-3 \xi / \xi_{95}}\right] \mathrm{s}_{\mathrm{u}, \text { ref }} \quad \text { (Power law) } \\
& \mathrm{s}_{\mathrm{u}}=\left[1+\mu \log \left(\frac{\operatorname{Max}\left(\mid \& \&_{\mathrm{ref}}\right)}{\&_{\mathrm{ref}}}\right)\right]\left[\delta_{\text {rem }}+\left(1-\delta_{\text {rem }}\right) \mathrm{e}^{-3 \xi / \zeta_{95}}\right] \mathrm{s}_{\mathrm{u}, \text { ref }} \quad \text { (Logarithmic law) }
\end{aligned}
$$

The definitions are given under notation list. Equation 1 was used for simulating dynamic installations involving high velocity, whereas Equation 2 was used for quasi-static monotonic pullout simulations. The first and second bracketed term of Equations 1 and 2 model the augmentation and degradation of strength, respectively. The augment of shear strength follows a power law with $\beta$ and logarithmic law with $\mu$, respectively. From the previous studies on field and centrifuge tests in various clays, typical values of $\beta$ and $\mu$ are in the range of 0.05 1.0 and 0.09 0.15, respectively (Biscontin and Pestana, 2001; Chung et al., 2006; Boylan et al., 2007; Peuchen and Mayne, 2007; Lehane et al., 2009; Low et al., 2010; Boukpeti et al., 2012; Steiner et al., 2014; Chow et al., 2014). Recent researches have reported higher values for calcareous silts of $\beta=0.13 \sim 0.23$ and $\mu=0.27 \sim 0.35$ (Boukpeti and White, 2011; Gaudin et al., 2013; Hossain et al., 2015). Further details of the soil model can be found in Hossain and Randolph (2009), Zheng et al. (2015) and Kim and Hossain (2015, 2016, 2017). 
The elastic behaviour was defined by a Poisson's ratio of 0.49 and Young's modulus of $500 \mathrm{~s}_{\mathrm{u}}$ throughout the soil profile. Total stress analyses were carried out adopting a uniform effective unit weight $\left(\gamma^{\prime}\right)$ of $6 \mathrm{kN} / \mathrm{m}^{3}$ over the soil depth, representing a typical average value for field conditions. Typical computation times on a high performance workstation with 12 CPU cores were about 10 days for an anchor dynamic installation followed by monotonic pullout of $~ 2.5$ anchor lengths.

To the authors' knowledge, so far, there are two numerical modelling techniques for the frictional contact of anchor-soil interface in the CEL: (a) general contact method (Kim et al., 2015a; Kim and Hossain, 2015); and (b) reaction force method (Liu et al., 2016a). The former is modelled using a general contact algorithm in ABAQUS, while the latter is modelled using a concentrate force as a frictional resistance. Liu et al. (2016a) presented a direct comparison between these two methods against field measured data. Both methods have shown the capability and accuracy in assessing the embedment depth during dynamic installation of DIAs in non-homogeneous clay. However, the considered reaction force method is only applicable for vertical installation i.e. not for pullout.

In this study, the soil-anchor interface was modelled as frictional contact, using a general contact method and specifying a Coulomb friction law together with a limiting shear stress $\left(\tau_{\max }\right)$ along the anchor-soil interface. The Coulomb friction coefficient was deliberated set to a high value of $\mu_{C}=50$, in order to allow the value of $\tau_{\max }$ to govern failure. Within the CEL, the value of the limiting interface friction must be set prior to the analysis, before the value of the 'adjacent' soil strength is known. To overcome this difficulty, for each case, the limiting interface friction was determined by: (1) simulating anchor penetration with frictionless contact; (2) obtaining the final anchor tip penetration depth and calculating $\mathrm{s}_{\mathrm{u}, \mathrm{ref}}$ at that depth; and (3) setting $\tau_{\max }$ equal to an interface friction ratio, $\alpha$, times the calculated $s_{u, r e f}$ at the final 
tip depth (from frictionless contact), with $\alpha$ taken as the inverse soil sensitivity, $1 / \mathrm{S}_{\mathrm{t}}$. Due to the limitation of the current CEL approach, $\tau_{\max }$ is a constant value along the anchor surfaces during the entire calculation. At shallow depth, where $\tau_{\max }$ may exceed the rate dependent shear strength of the adjacent soil, failure may occur at the nearest integration points, rather than at the interface. The contact interface is created between Lagrangian mesh and Eulerian material, and automatically computed and tracked during the analysis, which is essential for the pullout simulations.

The numerical model has previously been used in investigating performance of torpedo and OMNI-Max DIAs (Kim et al., 2014, 2015a; Kim and Hossain, 2015, 2017). The results have been validated against existing field data and centrifuge test data, confirming the capability and accuracy of the numerical model in assessing the installation depth, keying and diving of anchors DIAs in non-homogeneous clay and calcareous silt. For the novel fish DIA, there is no field data, and validation against centrifuge test data was carried out later while discussing installation and performance.

\section{RESULTS AND DISCUSSION: ANCHOR INSTALLATION}

To examine the effect of various factors on the embedment depth, an extensive parametric study was carried out varying (a) impact velocity ( $\mathrm{v}_{\mathrm{i}}=15 \sim 25 \mathrm{~m} / \mathrm{s}$ ); (b) the soil undrained shear strength $\left(\mathrm{s}_{\mathrm{u}, \mathrm{ref}}=2.4+1.1 \mathrm{z} \mathrm{kPa}, 5+2 \mathrm{z} \mathrm{kPa}\right.$ and $\left.10+3 \mathrm{z} \mathrm{kPa}\right)$; and (c) the soil type (kaolin clay and calcareous silt; $\mathrm{s}_{\mathrm{u}, \mathrm{ref}}=1.6+1 \mathrm{z} \mathrm{kPa}$ ) as assembled in Table 2. The DIA dynamic installation was modelled from the soil surface, with a given velocity $\mathrm{v}_{\mathrm{i}}$. To predict accurate embedment depth involving high velocity, the power law soil model (Equation 1) was considered. Parameters in terms of rate dependency and strain-softening of clay soil were 
taken as $\beta=0.05 ; \xi_{\text {ref }}=0.1 \mathrm{~s}^{-1} ; \delta_{\text {rem }}=1 / 3$; and $\xi_{95}=20$, as they provided good match in the previous validation exercise (Kim et al., 2015a).

\subsection{Anchor velocity and embedment depth in clay}

Figure 4 depicts the instantaneous (resultant) velocity vectors during penetration of the fish DIA (in Table 1 referring to anchor F3, see also Figure 1) in clay. It shows the soil failure mechanisms at 4 different times after impacting the soil surface: (a) immediately after impacting the seafloor $(t=0.15 \mathrm{~s}$; Figure 4a); (b) at $\mathrm{t}=0.5 \mathrm{~s}$ (Figure $4 \mathrm{~b})$, significant soil movement occurs adjacent to the anchor head part (e.g. anchor head, body fins and padeye); (c) at $\mathrm{t}=1.0 \mathrm{~s}$ (Figure 4c), the soil incremental displacement also occurs at the tail fins due to the backfilled soil; (d) finally $\mathrm{t}=1.5 \mathrm{~s}$ (Figure 4c), the velocities in the soil decrease towards zero as the anchor reaches its final embedment depth i.e. comes to the rest. Based on the failure mechanisms, the DIA penetration profile can be divided into two stages (see Figure 4). Stage 1 corresponds to shallow penetration where the DIA accelerates although it advances into the soil. The soil resistance is less than the submerged weight of the anchor. The depth of this acceleration stage (stage 1) mainly depends on the DIA submerged weight and impact velocity. In stage 2, at greater penetration, the frictional and end bearing resistance, along with the inertial drag, outweigh the submerged weight and the DIA decelerates.

To show the effect of impact velocity $\left(\mathrm{v}_{\mathrm{i}}\right)$, DIA velocity profiles for $\mathrm{v}_{\mathrm{i}}=15,19$ and $25 \mathrm{~m} / \mathrm{s}$ are plotted together in Figure 5 (Group I, Table 2). From Figure 5, the net increase in velocity at shallow embedment (stage 1) reduces as the impact velocity increases. This is to be expected as the impact velocity approaches closer to the DIA's terminal velocity, less acceleration occurs within the soil (note, the terminal impact velocity of $\sim 35 \mathrm{~m} / \mathrm{s}$ was not considered as that high velocity is barely targeted in the field; e.g. Lieng et al., 2010). This is also associated with a reduction in the DIA penetration depth at which the DIA begins to 
decelerate (see Figure 5). A consistent trend was reported by O’Loughlin et al. (2013), Kim et al. (2015b) and Kim and Hossain (2015) analysing centrifuge model test data and LDFE results. Overall, the embedment depth increases as $d_{e, t}=23.77,25.7,29.26 \mathrm{~m}$ with increasing impact velocity as $\mathrm{v}_{\mathrm{i}}=15,19,25 \mathrm{~m} / \mathrm{s}$.

\subsection{Effect of undrain shear strength in clay}

Figure 6 shows the effect of the undrained shear strength of soil $\left(\mathrm{s}_{\mathrm{u}, \mathrm{ref}}=2.4+1.1 \mathrm{z}, 5+2 \mathrm{z}, 10\right.$ $+3 \mathrm{z} \mathrm{kPa})$ and impact velocity $\left(\mathrm{v}_{\mathrm{i}}=15,19,25 \mathrm{~m} / \mathrm{s}\right)$ on the final embedment depth of the fish DIA (F3, Table 1) in clay. The results for calcareous silt are also included in this figure (will discuss later). The overall trend indicates that the embedment depth reduces with increasing soil strength. The reverse trend is evident with increasing impact velocity. The different undrained shear strength profiles and corresponding embedment depths also affect the cavity formation above the installed DIA, as shown in Figure 7. Although the hole above the embedded DIA is not fully replenished, it can be seen that (a) for clay with $\mathrm{s}_{\mathrm{u}, \mathrm{ref}}=2.4+1.1 \mathrm{z}$ $\mathrm{kPa}$ and $\mathrm{d}_{\mathrm{e}, \mathrm{t}}=23.77 \mathrm{~m}$ (Figures 7a and 7d), the anchor becomes essentially fully covered by the backfilled soil; and (b) for clay with $\mathrm{s}_{\mathrm{u}, \mathrm{ref}}=5+2 \mathrm{z} \mathrm{kPa}, \mathrm{d}_{\mathrm{e}, \mathrm{t}}=25.7 \mathrm{~m}$ and $\mathrm{s}_{\mathrm{u}, \mathrm{ref}}=10+3 \mathrm{z}$ $\mathrm{kPa}, \mathrm{d}_{\mathrm{e}, \mathrm{t}}=19.26 \mathrm{~m}$ (Figures 7b, 7c and 7d), the soil partly flows back between the tail and the body fins, but the cavity remains fully open (with distorted walls). The depth of an open cavity above a penetrating object can be explained by a dimensionless strength ratio $\mathrm{s}_{\mathrm{u}, \mathrm{ze}} / \gamma^{\prime} \mathrm{D}_{\mathrm{p}}$ (Hossain et al., 2005; Morton et al., 2014; O’Beirne., 2015; Chang et al., 2017) where $z_{e}$ is the depth of the widest part of the penetrating object and $\mathrm{s}_{\mathrm{u}, \mathrm{ze}}$ is the soil strength at $\mathrm{z}_{\mathrm{e}}$. All the results of the fish anchor form this study are plotted in Figure 8. The experimental data for projectiles from O’Beirne et al. (2015), previous LDFE results for two different DIAs (T-98 and OMNI-Max; Kim et al., 2015a and Kim and Hossain, 2015) and the expression proposed by Morton et al. (2014) for dynamic ball penetrometer are also included in Figure 8 for 
comparison. The formed cavity conditions above the installed fish DIA are consistent with and well expressed by the expression line of Morton et al. (2014). The overall trend is also similar to other DIAs.

\subsection{Anchor installation in calcareous silt}

For calcareous silt, the soil model was validated against centrifuge test data prior to undertaking a detailed parametric study. Chang et al. (2017) presented data from a centrifuge test carried out at 133.3g in calcareous silt. The model fish anchor, manufactured from stainless steel with the geometry identical to the one considered in this study (anchor F4, Table 1), was dropped dynamically. The achieved impact velocity ranged from 17.84 to 22.45 $\mathrm{m} / \mathrm{s}$. The soil undrained shear strength of $\mathrm{s}_{\mathrm{u}, \mathrm{ref}}=1+1.6 \mathrm{z} \mathrm{kPa}$ was deduced from $\mathrm{T}$-bar penetration tests. The sensitivity of the calcareous silt was $S_{t}=3.0$, as judged from cyclic Tbar tests. The average impact velocity of $19 \mathrm{~m} / \mathrm{s}$ was chosen for the validation exercise. In the LDFE simulation, these parameters and $\delta_{\text {rem }}=1 / S_{\mathrm{t}}=1 / 3 ; \xi_{95}=20$; and $\xi_{\text {ref }}=0.1 \mathrm{~s}^{-1}$ were used. In order to find an appropriate value for the rate parameter for the calcareous silt, $\beta$ (Equation 1) was varied between 0.05 and 0.3 . Figure 9 shows the effect of $\beta$ on the embedment depth. In general, the embedment depth reduces with increasing $\beta$, indicating the effect of enhanced undrained shear strength. The deepest embedment depth is obtained for $\beta=0.05$, which is identical to the value obtained for kaolin clay, as discussed previously and also noted by Boukpeti et al. (2012) and Kim et al. (2015a). $\beta=0.23$ provides the best fit with the measured embedment depths in the calcareous silt. Although $\beta=0.23$ is the upper bound of the range $\beta=0.13 \sim 0.23$ given for calcareous silt by Boukpeti and White (2011), it is greater than the range $\beta=0.145 \sim 0.16$ obtained through back-calculation of DIAs test data in calcareous silt (Hossain et al., 2014, 2015; Chang et al., 2017). As discussed previously, along 
with the stronger rate dependency, the dilative behaviour, as opposed to contractive behaviour of clay, also dictates the DIA behaviour in calcareous silt. The dilative behaviour cannot be captured using the extended Tresca soil model. Therefore, the upper bound value of $\beta=0.23$ was chosen for the further parametric analyses.

The effect of impact velocity $\left(\mathrm{v}_{\mathrm{i}}\right)$ for calcareous silt has already plotted in Figure 6 (anchor F4, Table 1), showing increasing embedment depth with increasing impact velocity. In the calcareous silt with undrained shear strength $\mathrm{s}_{\mathrm{u}, \mathrm{ref}}=1+1.6 \mathrm{z} \mathrm{kPa}$, the anchor tip embedment $\left(\mathrm{d}_{\mathrm{e}, \mathrm{t}}\right)$ ranges from 1.21 to $1.7 \mathrm{~L}_{\mathrm{A}}\left(\mathrm{v}_{\mathrm{i}}=15 \sim 30 \mathrm{~m} / \mathrm{s}\right.$; Group II, Table 2). This range for fish DIA is slightly higher than the ranges obtained from centrifuge model tests on other DIAs in calcareous silt: $1.14 \mathrm{~L}_{\mathrm{A}}$ to $1.46 \mathrm{~L}_{\mathrm{A}}\left(\mathrm{v}_{\mathrm{i}}=20.53 \sim 29.39 \mathrm{~m} / \mathrm{s}\right)$ and $1.0 \mathrm{~L}_{\mathrm{A}}$ to $1.46 \mathrm{~L}_{\mathrm{A}}\left(\mathrm{v}_{\mathrm{i}}=\right.$ 21.2 22.7 m/s) for OMNI-Max DIAs reported respectively by Gaudin et al. (2013) and Wei et al. (2015), and $0.96 \mathrm{~L}_{\mathrm{A}}$ to $1.4 \mathrm{~L}_{\mathrm{A}}\left(\mathrm{v}_{\mathrm{i}}=15.0 \sim 22.0 \mathrm{~m} / \mathrm{s}\right)$ for torpedo DIAs reported by Hossain et al. (2014, 2015). All these results will be used for developing a quantitative design chart in the following section.

\subsection{Modified energy method}

Considering the difference of soil undrained shear strength, anchor dimension and mass used in these studies, it is necessary to remove the dependence of these variables for comparing the penetration efficiency of various DIAs. Recently, O’Loughlin et al. (2013), Kim et al. (2015a, 2015b), Hossain et al. (2015) and Kim and Hossain (2015, 2016) proposed a simple expression using the total energy concept to predict the penetration depth for DIAs in single layer clay or silt deposits. Total energy ( $\left.E_{\text {total }}\right)$, defined as the sum of the kinetic and potential energy (relative to the final embedment depth) of the DIA at the mudline, normalised by DIA total surface area $\left(\mathrm{A}_{\mathrm{s}}\right)$, an effective soil strength gradient $\left(\mathrm{k}_{\mathrm{eff}}=\left(\mathrm{s}_{\mathrm{um}, \mathrm{ref}}+\mathrm{kd} \mathrm{d}_{\mathrm{e}, \mathrm{t}}\right) / \mathrm{d}_{\mathrm{e}, \mathrm{t}}\right)$ and DIA 
projected area equivalent diameter (including fins, $\mathrm{D}_{\mathrm{p}}$ ); was expressed in terms of normalised embedment depth $\left(\mathrm{d}_{\mathrm{e}, \mathrm{t}} / \mathrm{D}_{\mathrm{p}}\right)$ as

$$
\frac{\mathrm{d}_{\mathrm{e}, \mathrm{t}}}{\mathrm{D}_{\mathrm{p}}} \approx \mathrm{q}\left(\frac{\mathrm{E}_{\text {total }}}{\mathrm{k}_{\mathrm{eff}} \mathrm{A}_{\mathrm{s}} \mathrm{D}_{\mathrm{p}}{ }^{2}}\right)^{\mathrm{r}}
$$

where

$$
\mathrm{E}_{\text {total }}=\frac{1}{2} \mathrm{mv}_{\mathrm{i}}^{2}+\mathrm{m}^{\prime} \mathrm{gd}_{\mathrm{e}, \mathrm{t}}
$$

with $\mathrm{m}^{\prime}$ being the effective mass of the DIA (submerged in soil), g Earth's gravitational acceleration of $9.81 \mathrm{~m} / \mathrm{s}^{2}$. Figure 10 compares the measured data and computed results. For clay, the data for OMNI-Max DIAs reported by Zimmerman et al. (2009) and Kim and Hossain (2015) are consistent with the results for the fish anchor from this study. Although Equation 3 with $q=2.46$ and $r=0.37$ originally proposed for OMNI-Max DIAs (Kim and Hossain, 2015), those numbers still show a good prediction for the fish DIA in clay.

For calcareous silt, (i) DIAs embedment depths are around 34\% lower than those for clay, (ii) the measured (Chang et al., 2017) and computed (from this study) results for the fish DIAs are agrees reasonably with the measured data for OMNI-Max DIAs (Gaudin et al., 2013; Wei et al., 2015). Although the data are slightly scattered, the best fit through all the data using Equation 3 provides $\mathrm{q}=1.65$ and $\mathrm{r}=0.37$.

\section{RESULTS AND DISCUSSION: ANCHOR KEYING AND DIVING}

In order to investigate the pullout behaviour of the fish DIA, an extensive parametric study was carried out varying the (a) padeye offset ratio, $\eta$, and (b) pullout angle at the padeye, $\theta_{\mathrm{a}}$. For the quasi-static monotonic pullout simulation, the logarithmic law (Equation 2) was adopted in the clay soil model. Parameters in terms of rate dependency and strain-softening 
were taken as $\mu=0.1 ; \xi_{\text {ref }}=1.5 \% \mathrm{~h}^{-1} ; \xi_{95}=20$, as they provided good match in the validation exercise in clay (Kim and Hossain, 2017). An inclined pullout loading, rather than an inclined displacement, was applied to the anchor padeye $\left(\theta_{a}\right)$ to obtain apparent anchor trajectory. The results from this parametric study, as assembled in Table 1 and Table 2, are discussed below. For the comparison purpose, the results from LDFE analyses on the OMNIMax DIA analyses (Kim and Hossain 2017) are plotted together.

\subsection{Effect of padeye offset ratio, $\eta$}

The diving efficiency was assessed varying the padeye offset ratio ( $\eta)$. As shown in Figure 1, $\eta$ can be defined as the ratio of $e_{p}$ and $e_{n}$ (where $e_{n}$ denotes the padeye eccentricity and $e_{p}$ represents the padeye offset relative to the anchor centroid point). For the Omni-Max DIA, Kim and Hossain (2017) highlighted the influence of $\eta$ on the tendency of diving under monotonic pullout loading. The same concept was adopted here for assessing diving potential of the fish DIA. In order to investigate the effect of $\eta$ on the anchor traveling path, the fish DIAs with five different padeye offset ratios of $\eta=0.1 \sim 0.9$ (anchor F1 $\sim$ F5, Table 1 ) were installed under an identical impact velocity $\left(\mathrm{v}_{\mathrm{i}}\right)$ of $19 \mathrm{~m} / \mathrm{s}$. The achieved embedment depths were similar $\left(\mathrm{d}_{\mathrm{e}, \mathrm{t}}=25.3 \sim 25.8 \mathrm{~m}\right.$; Group III, Table 2). The anchors were then pulled out at an angle at the padeye of $\theta_{a}=30^{\circ}$.

Figure 11 depicts the typical DIA diving trajectories for $\eta=0.4$ and corresponding failure mechanisms. It shows the pullout track of the fish DIA can be divided into two main stages: (a) keying; (b) diving. At the beginning of the keying process (between location (a) and location (c) in Figure 11), the soil adjacent to the DIA head fins (tip) moves significantly and faster, while the soil around to the DIA tail fins moves marginally (see inset figure). This indicates that the DIA rotates or keying occurs at this stage. At the end of the keying process 
(location (c) in Figure 11), more mobilisation of soil movement can be seen around to the DIA tail fins, indicating translation of the DIA with minor rotation. In the diving stage (location (d) in Figure 11), the DIA moves into deeper soil with a constant angle (defined as $\varphi)$, and a significant soil movement occurs around the DIA.

Figures $12 \mathrm{a}$ and $12 \mathrm{~b}$ show respectively the centroid traveling direction and corresponding stabilised travelling angle $(\varphi)$ of the fish DIA and the evolution of the DIA tip inclination angle $\left(\alpha_{\text {in }}\right)$. Figure 12a confirms that the DIA keying process and potential diving are strongly dependent on the padeye offset ratio $(\eta)$. The initial loss of embedment during the keying process increases, and the travelling angle $\varphi$ reduces, with decreasing $\eta$. For all the cases with $\eta=0.1 \sim 0.9$, the fish DIA dives into deeper soil with various diving tendencies or travelling angles i.e. $\varphi<0$.

Two curves for the Omni-Max anchor from Kim and Hossain (2017) are included in Figure 12a for comparison. It is clear that the diving efficiency of the fish DIA is far better than that of the OMNI-Max DIA. For instance, for the investigated smallest $\eta$ of 0.1 , the fish DIA dives in $(\varphi<0)$ whereas the OMNI-Max DIA lifts up straightway without keying or diving $(\varphi>0)$. For a similar $\eta$ of 0.21 for the fish DIA and 0.256 for the OMNI-Max DIA, the fish DIA dives earlier and much deeper meaning the initial loss of embedment during the keying process is lower, and the travelling angle of the fish DIA of $\varphi=-19.5^{\circ}$ is 2.4 time of that $\left(\varphi=-8.3^{\circ}\right)$ of the OMNI-Max DIA. One of the key reasons is the shifting of the centroid lower. The fish DIA was designed to be thicker in the head part than the tail part (see Figure $1)$, which makes the location of centroid mass $\left(0.44 \mathrm{~L}_{\mathrm{A}}\right.$ from the tip) to be lower than the centre of the DIA $\left(0.5 \mathrm{~L}_{\mathrm{A}}\right)$. 
Figure $12 \mathrm{~b}$ shows that the fish DIA inclination angle $\alpha_{\text {in }}$ reaches to a plateau or a stabilised stage when the anchor dives into the deeper soil. It means the anchor does not rotate any further, but maintains a constant trajectory. The stabilised inclination angle $\left(\alpha_{\mathrm{in}, \mathrm{s}}\right)$ reduces with increasing $\eta$ (see inset figure).

Figure 13 shows the pullout load-displacement profiles. The normalised pullout capacity, $\mathrm{F}_{\mathrm{N}} /\left(\mathrm{A}_{\mathrm{s}} \mathrm{s}_{\mathrm{u}, \mathrm{av}}\right)$ (where $\mathrm{F}_{\mathrm{N}}=\mathrm{F}-\mathrm{W}_{\mathrm{ss}}=$ net pullout resistance and $\mathrm{s}_{\mathrm{u}, \mathrm{av}}=$ average undrained shear strength over the anchor shaft length), is presented as a function of normalised drag distance, $\mathrm{u} / \mathrm{L}_{\mathrm{A}}$. As discussed previously, the pullout process can be divided into two stages. Due to the diving effect, the pullout capacity after the keying keeps increasing. The gradient or rate of increasing normalised pullout capacity increases with increasing travelling angle $\varphi$. This leads to even higher normalised pullout capacity of the fish DIA compared to the OMNI-Max DIA. For example, for a similar padeye offset ratio $(\eta)$, the gradient of the normalised pullout capacity curve after keying for the fish DIA $\left(\eta=0.4 ; \varphi=-25^{\circ}\right)$ is about 1.6 times higher compared to the OMNI-Max DIA $\left(\eta=0.35 ; \varphi=-15.8^{\circ}\right)$, leading to 1.4 times greater pullout capacity.

\subsection{Effect of pullout angle}

Figure 14 shows typical anchor trajectories (for $\eta=0.1$ and 0.4 ) under various pullout angles at the padeye of $\theta_{\mathrm{a}}=30^{\circ}$ and $45^{\circ}$ (in Groups III and IV, Table 2). Overall, for any $\eta$, the stabilised centroid travelling angle $\varphi$ decreases (including negative values) with reducing pullout angle $\theta_{\mathrm{a}}$. Two curves for the OMNI-Max DIA are also added in Figure 14 for comparison. Interestingly, for $\theta_{\mathrm{a}}=45^{\circ}$, both fish and OMNI-Max DIAs are lift up regardless of $\eta$, but the lifting angle $\varphi$ for the fish DIA is much smaller and much more gradual, meaning the anchor will travel a longer distance and the failure will be ductile. 
The relationship between the stabilised travelling angle, $\varphi$, and the padeye offset ratio, $\eta$, is shown in Figure 15 plotting all the results of Groups III and IV analyses (Table 2). All the different curves displayed in the figure show a similar pattern that the anchor stabilised travelling angle $\varphi$ varies with increasing padeye offset ratio $\eta$. The figure is divided into two zones, $\varphi<0$ indicates the DIA will dive into deeper soil, and $\varphi>0$ indicates the DIA will lift up. For $\theta_{a}=30^{\circ}$, the fish DIA dives in regardless of $\eta$, whereas the OMNI-Max dives in for $\eta>0.25$, although the optimum $\eta$ lies in the similar rage of $0.35 \sim 0.55$ for both DIAs. The diving efficiency of the fish DIA is significantly higher. For $\theta_{a}=45^{\circ}$, both DIAs lifts up, but the efficiency of the fish DIA in terms of gaining capacity, and reducing the likelihood of brittle/catastrophic failure, is higher.

\subsection{Anchor pullout trajectories in Calcareous silt}

Additionally, DIA trajectories in calcareous silt were investigated varying pullout angles at the padeye $\left(\theta_{\mathrm{a}}=18^{\circ}, 23^{\circ}\right.$ and $45^{\circ}$; Group $\mathrm{V}$ in Table 2). As noted previously, the identical anchor geometry (F4 in Table 1$)$ and soil strength $\left(\mathrm{s}_{\mathrm{u}, \text { ref }}=1+1.6 \mathrm{z} \mathrm{kPa}\right)$ were chosen from the centrifuge tests (Change et al., 2017). Being consistent with the dynamic installation (see Section 3.2), the upper bound rate parameter $(\mu=0.35$ ) from the typical range $(\mu=0.27 \sim 0.35$; Boukpeti and White, 2011) was adopted to capture the stronger rate dependency of the calcareous silt.

Figure 16 shows fish DIA trajectories in calcareous silt along with the measured data for the OMNI-Max and fish DIAs presented by Gaudin et al. (2013) and Chang et al. (2017), respectively. Note, in the tests, the anchor trajectory (e.g. anchor embedment depth) was measured manually by temporally stopping the centrifuge during pullout. Overall, the trend of pullout behaviour in calcareous silt is similar to that in clay. For example, smaller $\theta_{\mathrm{a}}$ reduces 
the loss of embedment, and thus results in an earlier transition from keying to diving, and also the DIA lifts up for higher $\theta_{\mathrm{a}}\left(\geq 45^{\circ}\right)$. The diving trend of the computed trajectories indicates reasonably consistent with the measured data. Compared to the OMNI-Max DIA with similar normalised embedment depth $\left(\mathrm{d}_{\mathrm{e}, \mathrm{t}} / \mathrm{L}_{\mathrm{A}}=1.3 \sim 1.4\right)$, the fish DIA shows a much earlier transition to diving and stiffer diving angle, meaning the fish DIA will lose less depth during the keying process and will penetrate deeper in the diving stage. Both of these are very critical and beneficial for DIAs in calcareous silt where the achieved embedment depths are relatively.

\section{CONCLUDING REMARKS}

This paper has reported the results from three-dimensional dynamic finite element analysis undertaken on a novel fish DIA aiming at introducing the DIA and assessing its performance, against other DIAs, during dynamic installation and monotonic pullout in non-homogeneous clay and calcareous silt. Clearly, (i) during dynamic installation, the achieved normalised embedment depths of the fish DIA lie in the similar range of the OMNI-Max DIA, and (ii) during monotonic pullout, the fish DIA lost lower embedment depth in the keying process, and dove deeper in the both clay and calcareous silt. These are more critical and beneficial for calcareous silt where the achieved embedment depths are generally lower compared to those in clay. Regardless of the padeye offset ratio, the diving efficiency of the fish DIA, which dictates the potential gaining capacity, is significantly higher than those of the OMNI-Max DIA.

\section{ACKNOWLEDGEMENTS}

The research presented here was undertaken with support from the Australian Research Council (ARC) Project DE140100903. The work forms part of the activities of the Centre for

Offshore Foundation Systems (COFS), currently supported as a node of the Australian 
Research Council Centre of Excellence for Geotechnical Science and Engineering and as a Centre of Excellence by the Lloyd's Register Foundation. This support is gratefully acknowledged, as is the benefit of discussion with Dr. Dong Wang. 


\section{REFERENCES}

Biscontin, G., and Pestana, J.M. (2001). Influence of peripheral velocity on vane shear strength of an artificial clay. Geotechnical Testing Journal, 24(4), 423-429.

Boukpeti, N. and White, D.J. (2011). Strength characterisation of a carbonate silt across the solid-fluid boundary report no. GEO: 11549, MERIWA project no. M395. Crawley, Western Australia: Geomechanics Group, Centre for Offshore Foundation Systems, The University of Western Australia.

Boukpeti, N., White, D.J. and Randolph, M.F. (2012). Strength of fine-grained soils at the solid-fluid transition. Géotechnique, 62(3), 213-226.

Boylan, N., Long, M., Ward, D., Barwise, A. and Georgious, B. (2007). Full-flow penetrometer testing in Bothkennar clay. Proc. 6th Int. Offshore Site Investigation and Geotechnics Conf., London, 177-186.

Brandão, F.E.N., Henriques, C.C.D., de Araujo, J.B., Ferreira, O.C.G. and dos Santos Amaral, C. (2006). Albacora Leste field development - FPSO P-50 mooring system concept and installation. Proc. Offshore Technology Conf., Houston, OTC18243.

Chang, K, Hossain, M.S., Wang, D. and Kim, Y.H. (2017). Performance of a novel dynamically installed fish anchor in calcareous silt. submitted to Journal of Geotechnical and Geoenvironmental Engineering.

Chow, S.H., O’Loughlin, C.D. and Randolph, M.F. (2014). Soil strength estimation and pore poressure dissipation for free-fall piezocone in soft clay. Géotechnique, 64(10), 817827.

Chung, S.F., Randolph, M.F. and Schneider, J.A. (2006). Effect of penetration rate on penetrometer resistance in clay. to Journal of Geotechnical and Geoenvironmental Engineering, ASCE, 132(9), 1188-1196.

Dassault Systèmes (2012). ABAQUS, Version 6.12 EF Documentation. Rhode Island: Hibbitt, Karlsson and Sorensen, Inc. 
Einav, I. and Randolph, M.F. (2005). Combining upper bound and strain path methods for evaluating penetration resistance. International Journal of Numerical Methods in Engineering, 63(14), 1991-2016.

Gaudin, C., O’Loughlin, C.D., Hossain, M.S. and Zimmerman, E.H. (2013). The performance of dynamically embedded anchors in calcareous silt. Proc. Int. Conf. on Ocean, Offshore and Arctic Engineering, Nantes, France, OMAE2013-10115.

Hossain, M. S., Hu, Y., Randolph, M.F. and White, D.J. (2005). Limiting cavity depth for spudcan foundations penetrating clay. Géotechnique, 55(9), 679-690.

Hossain, M. S. and Randolph, M. F. (2009). Effect of Strain Rate and Strain Softening on the Penetration Resistance of Spudcan Foundations on Clay. International Journal of Geomechanics, ASCE, 9(3), 122-132.

Hossain, M.S., Kim, Y.H. and Gaudin, C. (2014). Experimental investigation of installation and pull-out of dynamically penetrating anchors in clay and silt. Journal of Geotechnical and Geoenvironmental Engineering, ASCE, 140(7), 04014026.

Hossain, M.S., O’Loughlin, C. and Kim, Y.H. (2015). Dynamic installation and monotonic pullout of a torpedo anchor in calcareous silt. Géotechnique, 65(2), 77-90.

Kim, Y.H. and Hossain, M.S. (2015). Dynamic installation of OMNI-Max anchors in clay: numerical analysis. Géotechnique, 65(12), 1029-1037.

Kim, Y.H. and Hossain, M.S. (2016). Numerical study on pull-out capacity of torpedo anchors in clay. Géotechnique Letters, 6(4), 1-8.

Kim, Y.H. and Hossain, M.S. (2017). Dynamic installation, keying and diving of OMNI-Max anchors in clay. Géotechnique, 67(1), 78-85.

Kim, Y.H., Hossain, M.S. and Wang, D. (2014). Numerical modelling of dynamic installation of a torpedo anchor in calcareous silt. Proc. Int. Offshore and Polar Engineering Conference, ISOPE, Busan, Korea, 687-692.

Kim, Y.H., Hossain, M.S., Wang, D. and Randolph, M.F. (2015a). Numerical investigation of dynamic installation of torpedo anchors in clay. Ocean Engineering, 108, 820-832. 
Kim, Y.H., Hossain, M.S. and Wang, D. (2015b). Effect of strain rate and strain softening on embedment depth of a torpedo anchor in clay. Ocean Engineering, 108, 704-715.

Lehane, B.M., O’Loughlin, C.D., Gaudin, C. and Randolph, M.F. (2009). Rate effects on penetrometer resistance in kaolin. Géotechnique, 59(1), 41-52.

Lieng, J.T., Tjelta, T.I. and Skaugset, K. (2010). Installation of two prototype deep penetrating anchors at the Gjoa Field in the North Sea. Proc. Offshore Technology Conf., Houston, OTC20758.

Liu, H., Xu, K. and Zhao, Y. (2016a). Numerical investigation on the penetration of gravity installed anchors by a coupled Eulerian-Lagrangian approach. Applied Ocean Research, 60, 94-108.

Liu, J., Lu, L. and Hu, Y. (2016b). Keying behavior of gravity installed plate anchor in clay. Ocean Engineering, 114, 10-24.

Low, H.E., Lunne, T., Andersen, K.H., Sjursen, M.A., Li, X. and Randolph, M.F. (2010). Estimation of intact and remoulded undrained shear strengths from penetration tests in soft clays. Géotechnique, 60(11), 843-859.

Mao, X. and Fahey, M. (2003). Behaviour of calcareous soils in undrained cyclic simple shear. Géotechnique, 53(8), 715-727.

Miao, G. and Airey, D. (2013). Breakage and ultimate states for a carbonate sand. Géotechnique, 63(14), 1221-1229.

Morton, J.P., O’Loughlin, C.D. and White, D.J. (2014). Strength assessment during shallow penetration of a sphere in clay. Géotechnique Letters, 4(4), 262-266.

Nie, C. and Shelton, J. (2011). Prediction of Gravity Installed Anchors Installation Penetration. Oceans' 11 MTS/IEEE KONA, IEEE, Hawaii, 1845-1849.

O’Beirne, C., O’Loughlin, C.D. and Gaudin, C. (2015). Soil response in the wake of dynamically installed projectiles. Géotechnique Letters, 5 (3), 53-160. 
O’Loughlin, C.D., Richardson, M.D., and Randolph, M.F. (2009). Centrifuge tests on dynamically installed anchors. Proc. Int. Conf. on Ocean, Offshore and Arctic Engineering, Honolulu, USA, OMAE2009-80238.

O’Loughlin, C.D., Richardson, M.D., Randolph, M.F. and Gaudin, C. (2013). Penetration of dynamically installed anchors in clay. Géotechnique, 63(11), 909-919.

Peuchen, J. and Mayne, P. (2007). Rate effects in vane shear testing. Proc. 6th Int. Offshore Site Investigation and Geotechnics Conf., London, 187-194.

Richardson, M.D. (2008). Dynamically installed anchors for floating offshore structures. PhD Thesis, The University of Western Australia, Crawley, Australia.

Richardson, M.D., O’Loughlin, C.D., Randolph, M.F. and Gaudin, C. (2009). Setup following installation of dynamic anchors in normally consolidated clay. Journal of Geotechnical and Geoenvironmental Engineering, ASCE, 135(4), 487-496.

Shelton, J.T., Nie, C. and Shuler, D. (2011). Installation penetration of gravity installed plate anchors-laboratory study results and field history data. Proc. Offshore Technology Conf., Houston, OTC22502.

Steiner A, Kopf A.J, L’Heureux J-S., Kreiter, S., Stegmann, S., Haflidason, H. and Moerz T. (2014). In situ dynamic piezocone penetrometer tests in natural clayey soils - a reappraisal of strain-rate corrections. Canadian Geotechnical Journal, 51, 272-288.

Tian, Y., Cassidy, M. J. and Gaudin, C. (2014). The influence of padeye offset on plate anchor re-embedding behaviour. Géotechnique Letters, 4(1), 39-44.

Young, D.F., Munson, B.R., Okiishi, T.H. and Huebsch, W.W. (2010). A brief introduction to fluid mechanics. John Wiley and Sons.

Wei, Q., Tian, Y., Cassidy, M.J., Gaudin, C. and O’Loughlin, C.D. (2015). Behaviour of OMNI-Max anchors under chain loading. Proc. Int. symposium on frontiers in offshore geotechnics, ISFOG, Oslo, Norway, 925-930.

Zhao, Y. Liu, H. and Li, P. (2016). An efficient approach to incorporate anchor line effects into the coupled Eulerian-Lagrangian analysis of comprehensive anchor behaviours. Applied Ocean Research, 59, 201-215. 
Zheng, J., Hossain, M.S. and Wang, D. (2015). New Design Approach for Spudcan Penetration in Nonuniform Clay with an Interbedded Stiff Layer. Journal of Geotechnical and Geoenvironmental Engineering, ASCE, 141(4), 04015003.

Zimmerman, E.H., Smith, M.W. and Shelton, J.T. (2009). Efficient gravity installed anchor for deep water mooring. Proc. Offshore Technology Conf., Houston, OTC20117. 
Table 1. Fish DIA details

\begin{tabular}{|c|c|c|c|c|c|c|}
\hline Description & $\begin{array}{l}\text { Symbol } \\
\text { (unit) }\end{array}$ & F1 & $\mathrm{F} 2$ & F3 & $\mathrm{F} 4^{*}$ & F5 \\
\hline Total anchor length & $\mathrm{L}_{\mathrm{A}}(\mathrm{m})$ & \multicolumn{5}{|c|}{11.0} \\
\hline Fin thickness & $\mathrm{t}_{\mathrm{F}}(\mathrm{m})$ & \multicolumn{5}{|c|}{0.1} \\
\hline $\begin{array}{l}\text { Anchor frontal projected area } \\
\text { equivalent diameter }\end{array}$ & $\mathrm{D}_{\mathrm{p}}(\mathrm{m})$ & \multicolumn{5}{|c|}{2.08} \\
\hline DIA volume & $\mathrm{V}_{\mathrm{A}}\left(\mathrm{m}^{3}\right)$ & \multicolumn{5}{|c|}{14.45} \\
\hline DIA dry weight & $\mathrm{W}_{\mathrm{d}}(\mathrm{kN})$ & \multicolumn{5}{|c|}{850} \\
\hline DIA submerged weight & $\mathrm{W}_{\mathrm{s}}(\mathrm{kN})$ & \multicolumn{5}{|c|}{702} \\
\hline Padeye offset & $e_{p}(m)$ & 0.18 & 0.37 & 0.716 & 1.14 & 1.618 \\
\hline Padeye eccentricity & $e_{n}(m)$ & 1.796 & 1.796 & 1.799 & 1.801 & 1.804 \\
\hline Offset angle & $\omega$ (deg.) & 5.7 & 11.6 & 21.7 & 32.3 & 41.9 \\
\hline Padeye offset ratio & $\eta^{\#}$ & 0.1 & 0.21 & 0.4 & 0.63 & 0.9 \\
\hline
\end{tabular}

*Centrifuge testing model fish DIA (Change et al., 2017)

${ }^{*} \eta=\tan \omega=e_{\mathrm{p}} / \mathrm{e}_{\mathrm{n}}$ (see Figure 1 ) 
Table 2. Summary of 3D LDFE analyses performed

\begin{tabular}{|c|c|c|c|c|c|c|c|c|}
\hline Group & Anchor & $\begin{array}{l}\mathrm{S}_{\mathrm{u}, \mathrm{ref}} \\
(\mathrm{kPa})\end{array}$ & $\begin{array}{c}\mathrm{V}_{\mathrm{i}} \\
(\mathrm{m} / \mathrm{s})\end{array}$ & $\begin{array}{l}d_{e, t} \\
(m)\end{array}$ & $\begin{array}{c}\theta_{\mathrm{a}} \\
\text { (deg.) }\end{array}$ & $\eta$ & $\begin{array}{c}\varphi \\
\text { (deg.) }\end{array}$ & Note \\
\hline \multirow{9}{*}{ I } & \multirow{9}{*}{ F3 } & \multirow{3}{*}{$2.4+1.1 z$} & 15 & 23.77 & \multirow{9}{*}{-} & \multirow{9}{*}{0.4} & \multirow{9}{*}{-} & \multirow{9}{*}{$\begin{array}{l}\text { Effect of impact } \\
\text { velocity and soil } \\
\text { strength }\end{array}$} \\
\hline & & & 19 & 25.7 & & & & \\
\hline & & & 25 & 29.26 & & & & \\
\hline & & & 15 & 17.85 & & & & \\
\hline & & $5+2 z$ & 19 & 19.8 & & & & \\
\hline & & & 25 & 22.9 & & & & \\
\hline & & \multirow{3}{*}{$10+3 z$} & 15 & 14.2 & & & & \\
\hline & & & 19 & 16.2 & & & & \\
\hline & & & 25 & 18.7 & & & & \\
\hline \multirow{4}{*}{ II } & \multirow{4}{*}{$\mathrm{F} 4$} & \multirow{4}{*}{$1+1.6 z$} & 15 & 13.37 & \multirow{4}{*}{-} & \multirow{4}{*}{0.63} & \multirow{4}{*}{-} & \multirow{4}{*}{$\begin{array}{l}\text { Installation in } \\
\text { calcareous silt }\end{array}$} \\
\hline & & & 19 & 14.75 & & & & \\
\hline & & & 25 & 16.9 & & & & \\
\hline & & & 30 & 18.7 & & & & \\
\hline \multirow{5}{*}{ III } & $\mathrm{F} 1$ & \multirow{5}{*}{$2.4+1.1 z$} & \multirow{5}{*}{19} & 25.8 & \multirow{5}{*}{30} & 0.1 & -15.2 & \multirow{5}{*}{$\begin{array}{l}\text { Effect of padeye } \\
\text { offset ratio }\end{array}$} \\
\hline & $\mathrm{F} 2$ & & & 25.8 & & 0.21 & -19.5 & \\
\hline & F3 & & & 25.7 & & 0.4 & -25 & \\
\hline & $\mathrm{F} 4$ & & & 25.5 & & 0.63 & -20.4 & \\
\hline & F5 & & & 25.3 & & 0.9 & -7.1 & \\
\hline \multirow{5}{*}{ IV } & $\mathrm{F} 1$ & \multirow{5}{*}{$2.4+1.1 z$} & \multirow{5}{*}{19} & 25.8 & \multirow{5}{*}{45} & 0.1 & 20.6 & \multirow{5}{*}{$\begin{array}{l}\text { Effect of pullout } \\
\text { angle }\end{array}$} \\
\hline & $\mathrm{F} 2$ & & & 25.8 & & 0.21 & 12 & \\
\hline & F3 & & & 25.7 & & 0.4 & 10.8 & \\
\hline & $\mathrm{F} 4$ & & & 25.5 & & 0.63 & 11.3 & \\
\hline & F5 & & & 25.3 & & 0.9 & 13.2 & \\
\hline \multirow{3}{*}{$\mathrm{V}$} & \multirow{3}{*}{$\mathrm{F} 4$} & \multirow{3}{*}{$1+1.6 z$} & \multirow{3}{*}{19} & \multirow{3}{*}{14.75} & 18 & \multirow{3}{*}{0.63} & -28.1 & \\
\hline & & & & & 23 & & -17.4 & trajectory in \\
\hline & & & & & 45 & & 40.2 & \\
\hline
\end{tabular}




\section{No of Figure: 16}

Figure 1. Schematic geometries of existing DIAs and fish DIA: (a) Torpedo DIA; (b) OMNI-Max DIA; (c) Fish DIA

Figure 2. Typical mesh used in 3D LDFE analysis: (a) Side view; (b) Anchor modelling

Figure 3. Mesh convergence studies of fish anchor: (a) Anchor installation; (b) Anchor pullout (followed by installation)

Figure 4. Instantaneous velocity vectors with DIA embedment (anchor F3; in Group I, Table 2)

Figure 5. Effect of impact velocity on DIA penetration profile (anchor F3; in Group I, Table 2)

Figure 6. Effect of various factors on DIA tip embedment depth (Groups I and II, Table 2)

Figure 7. Effect of soil strength on cavity condition above installed DIA (anchor F3; in Group I, Table 2): (a) $\mathrm{s}_{\mathrm{u}, \mathrm{ref}}=2.4+1.1 \mathrm{z} \mathrm{kPa}$; (b) $\mathrm{s}_{\mathrm{u}, \mathrm{ref}}=5+2 \mathrm{z} \mathrm{kPa}$; (c) $\mathrm{s}_{\mathrm{u}, \text { ref }}=10$ $+3 z \mathrm{kPa}$; (d) Plan view

Figure 8. Correlation diagram with cavity condition, penetration depth and soil strength

Figure 9. Effect of rate parameter on DIA embedment depth in calcareous silt (anchor F4; in Group II, Table 2)

Figure 10. Modified energy method for assessing DIA embedment depths in clay and calcareous silt (Groups I and II, Table 2) 
Figure 11. Typical fish DIA diving trajectories and corresponding failure mechanisms (in Group III, Table 2): (a) Before pulling out; (b) Keying; (c) Transition of diving; (d) Diving

Figure 12. Effect of DIA padeye offset ratio (Group III, Table 2): (a) Anchor trajectories at centroid; (b) Inclined angles at anchor tip

Figure 13. Comparisons of pullout resistance-drag distance profiles (in Group III, Table 2)

Figure 14. Effect of pullout angle on DIA trajectories (Groups III and IV, Table 2)

Figure 15. Design chart for DIA travelling angle as a function of padeye offset ratio and load inclination at padeye (Groups III and IV, Table 2)

Figure 16. Pullout behaviour in calcareous silt (Groups V, Table 2) 


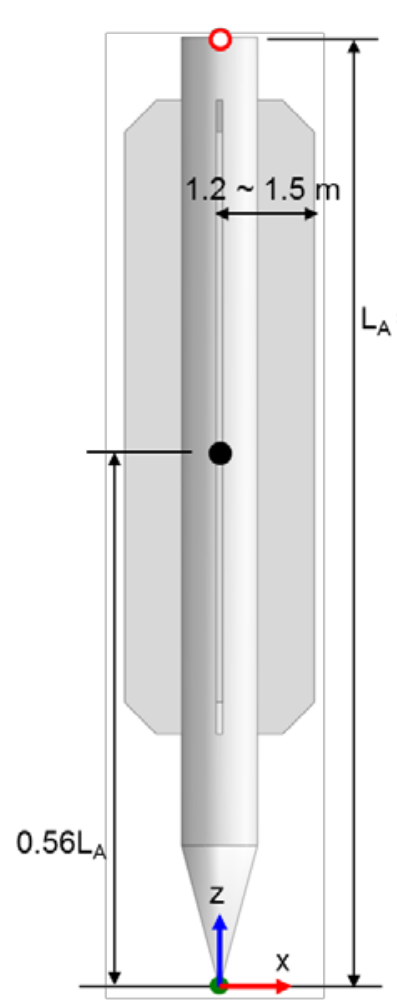

(a) Torpedo DIA

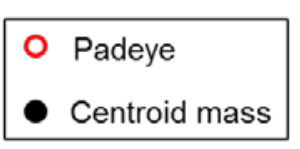

- Centroid mass

$L_{A}=15 \sim 17 \mathrm{~m}$

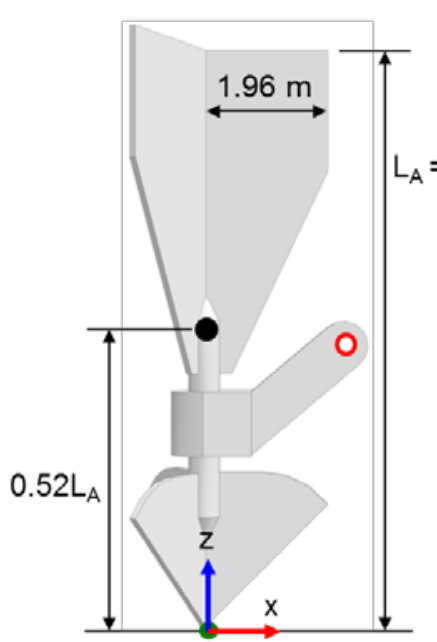

(b) OMNI-Max DIA

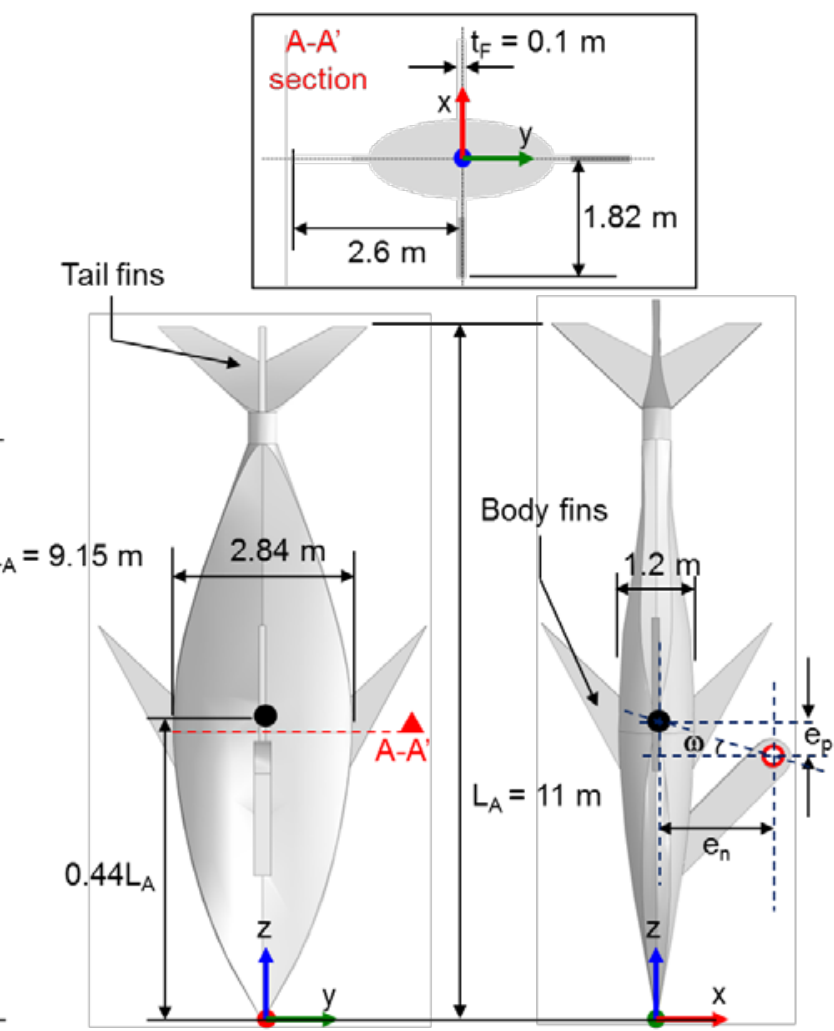

(c) Fish DIA

Figure 1. Schematic geometries of existing DIAs and fish anchor: (a) Torpedo DIA; (b)

OMNI-Max DIA; (c) Fish DIA 


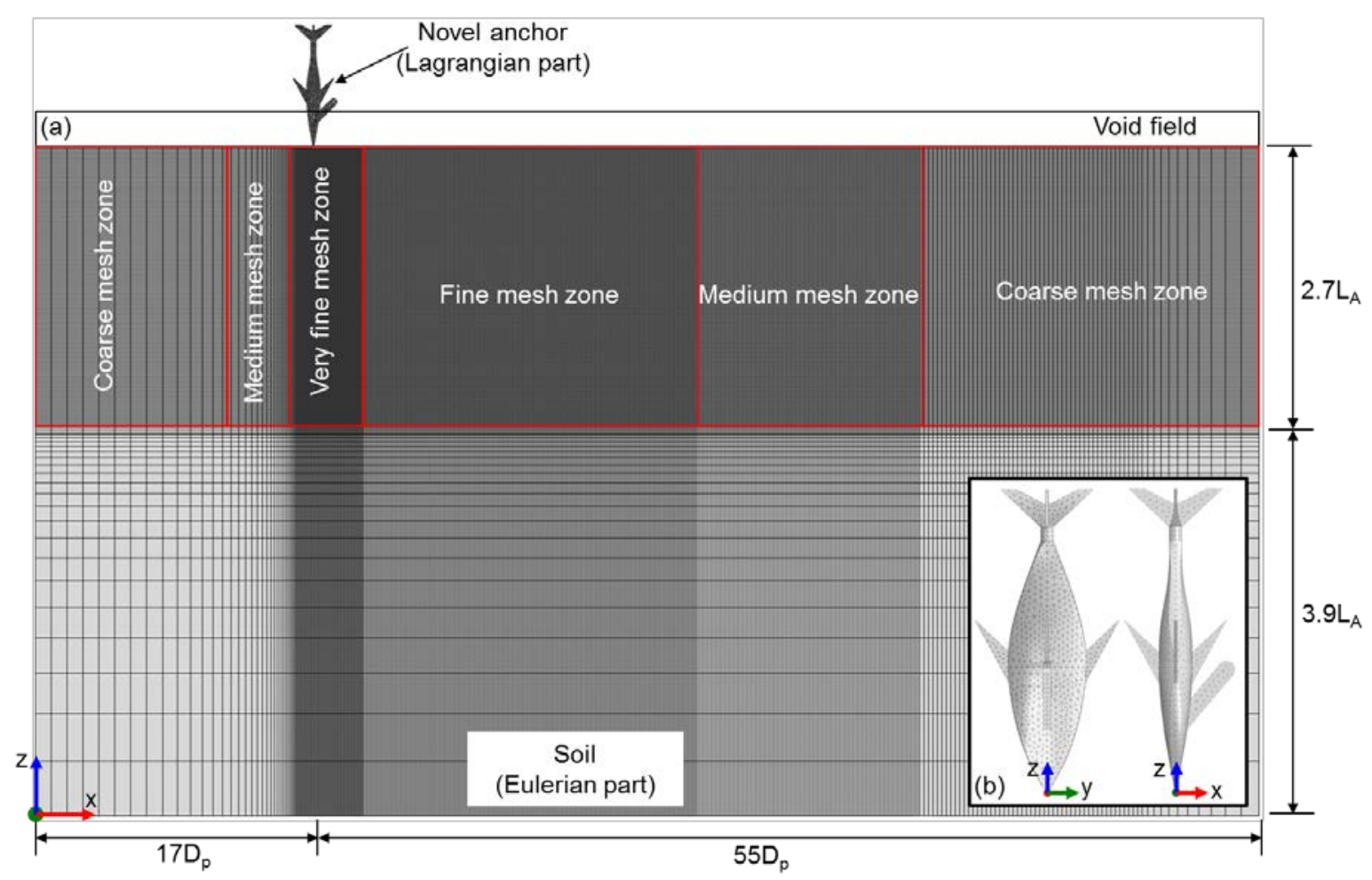

Figure 2. Typical mesh used in 3D LDFE analysis: (a) Side view; (b) Anchor modelling 


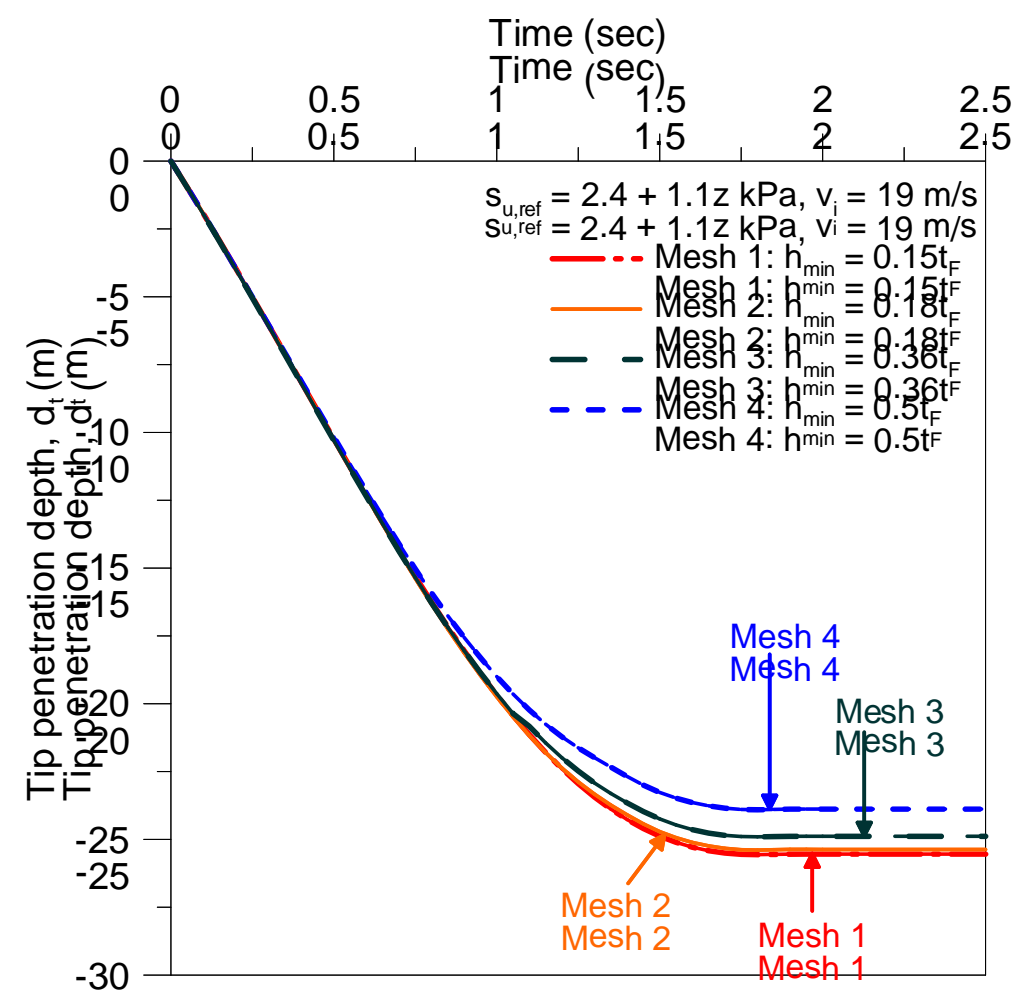

(a) Anchor installation

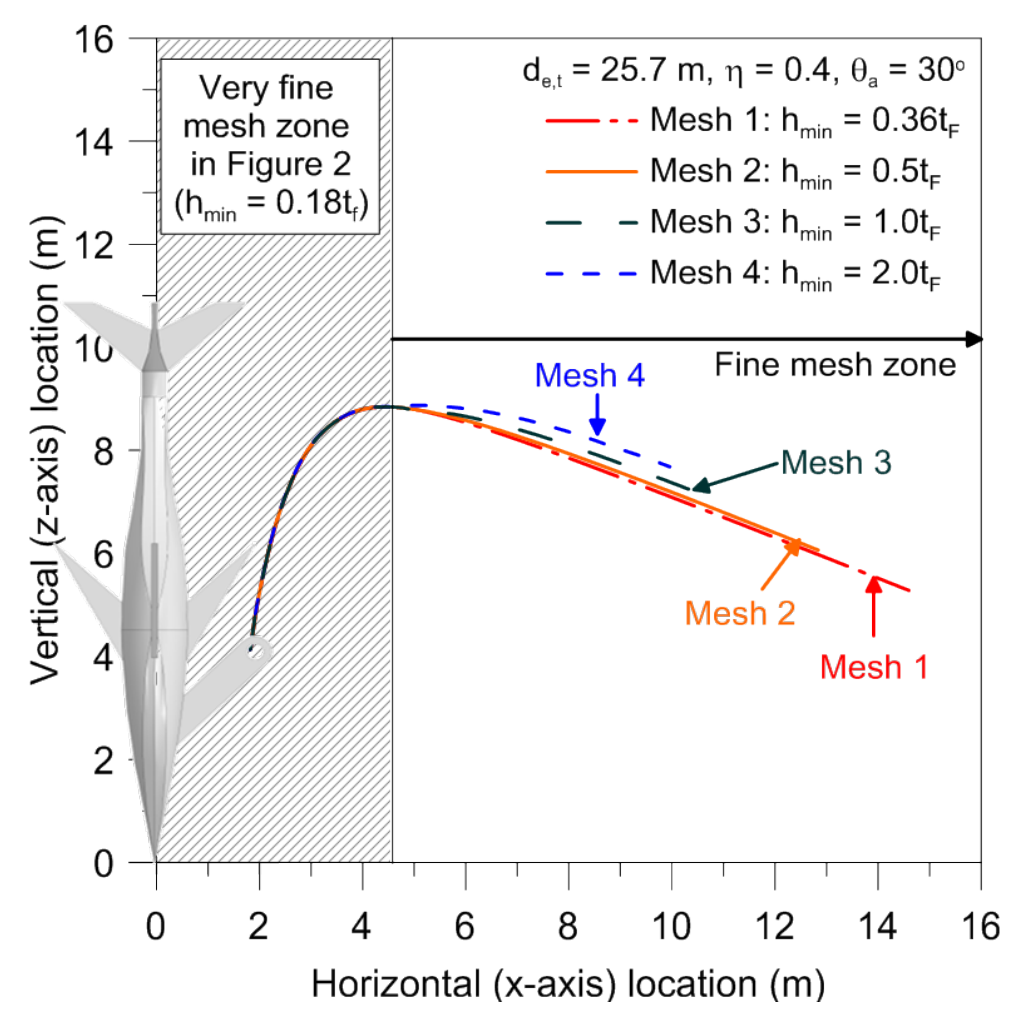

(b) Anchor pullout (followed by installation)

Figure 3. Mesh convergence studies of fish anchor 


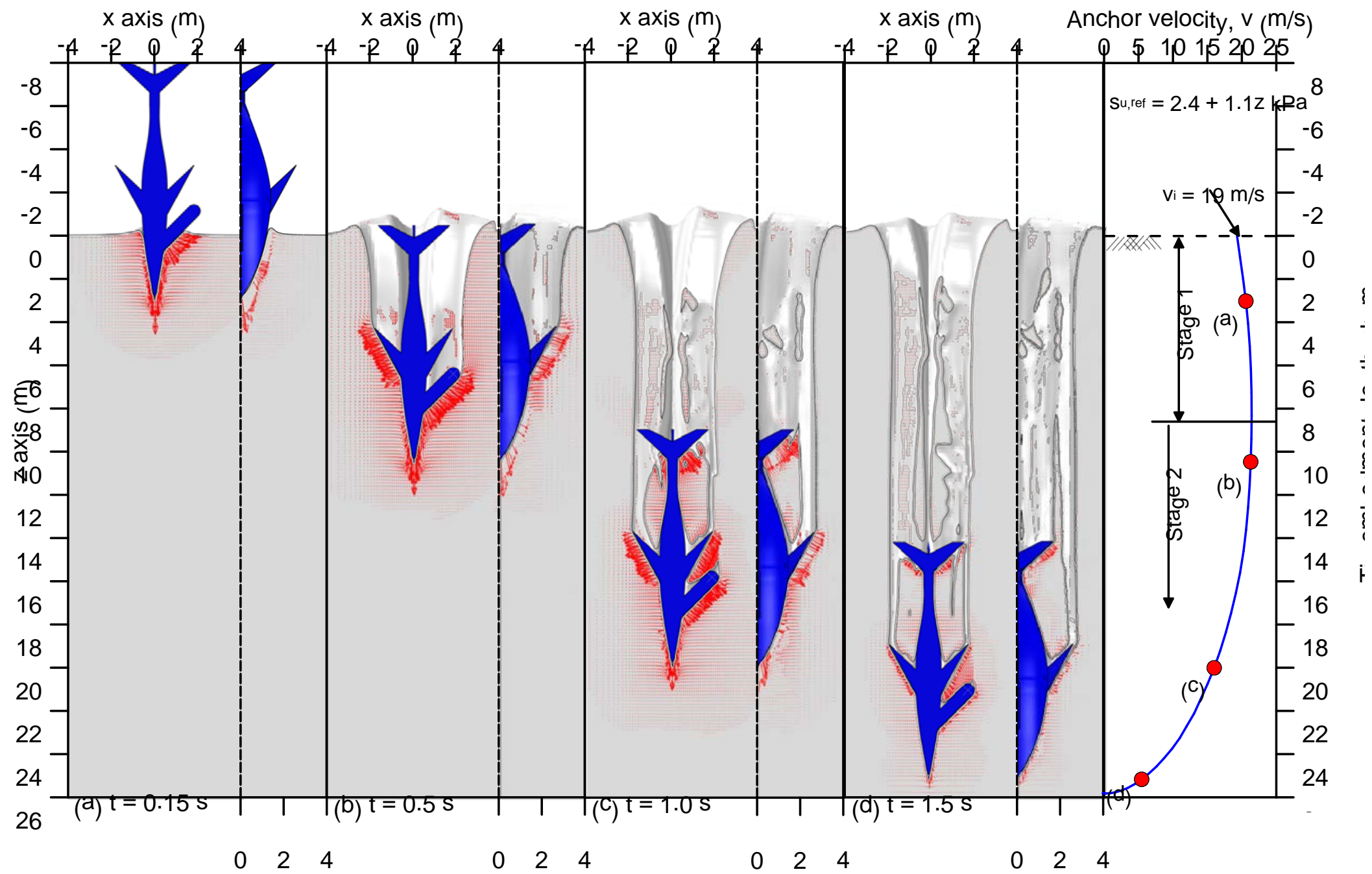

Figure 4. Instantaneous velocity vectors with anchor embedment (anchor F3; in Group I, Table 2) 


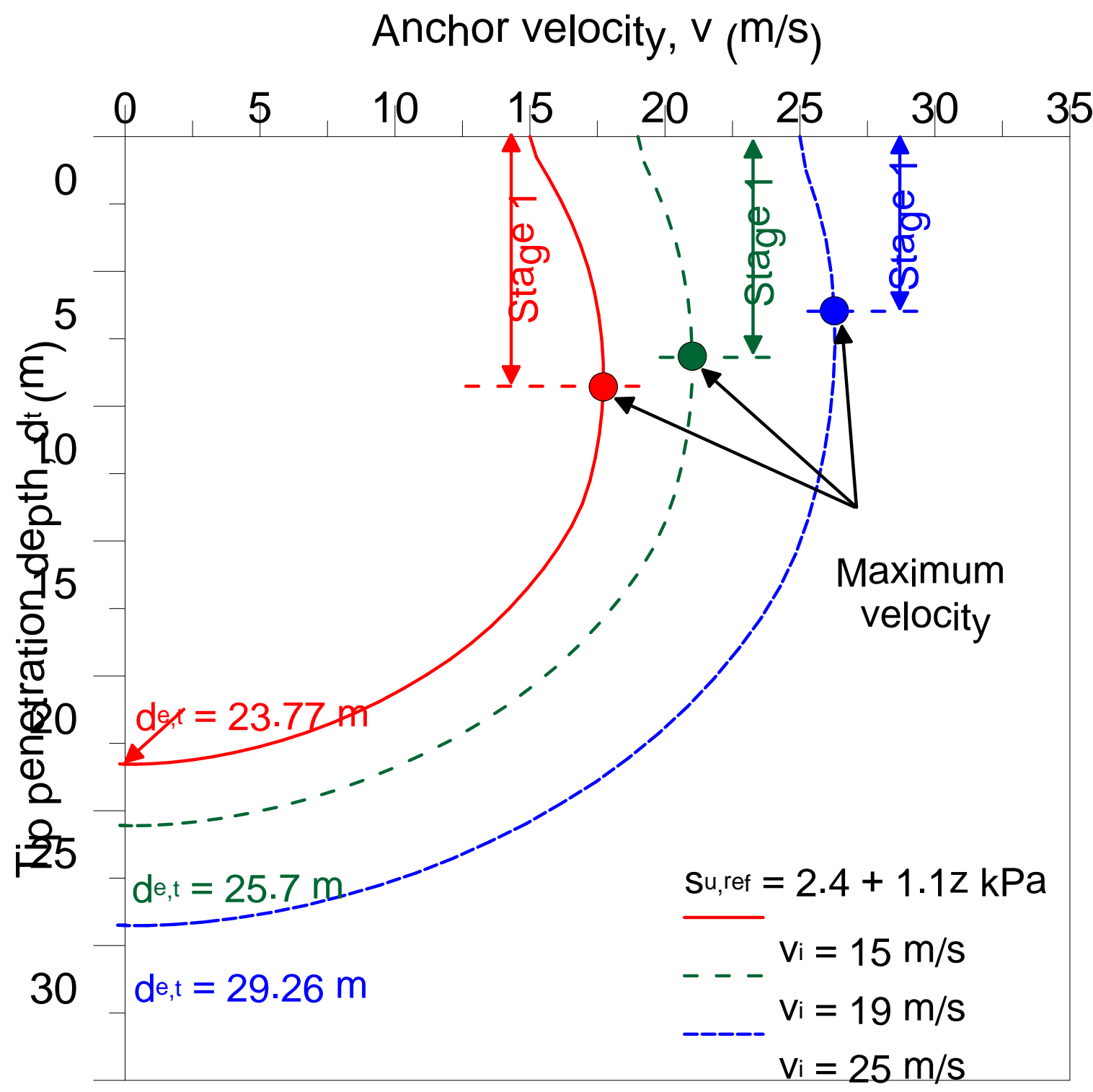

Figure 5. Effect of impact velocity on penetration profile (anchors F3; in Group I, Table 2) 


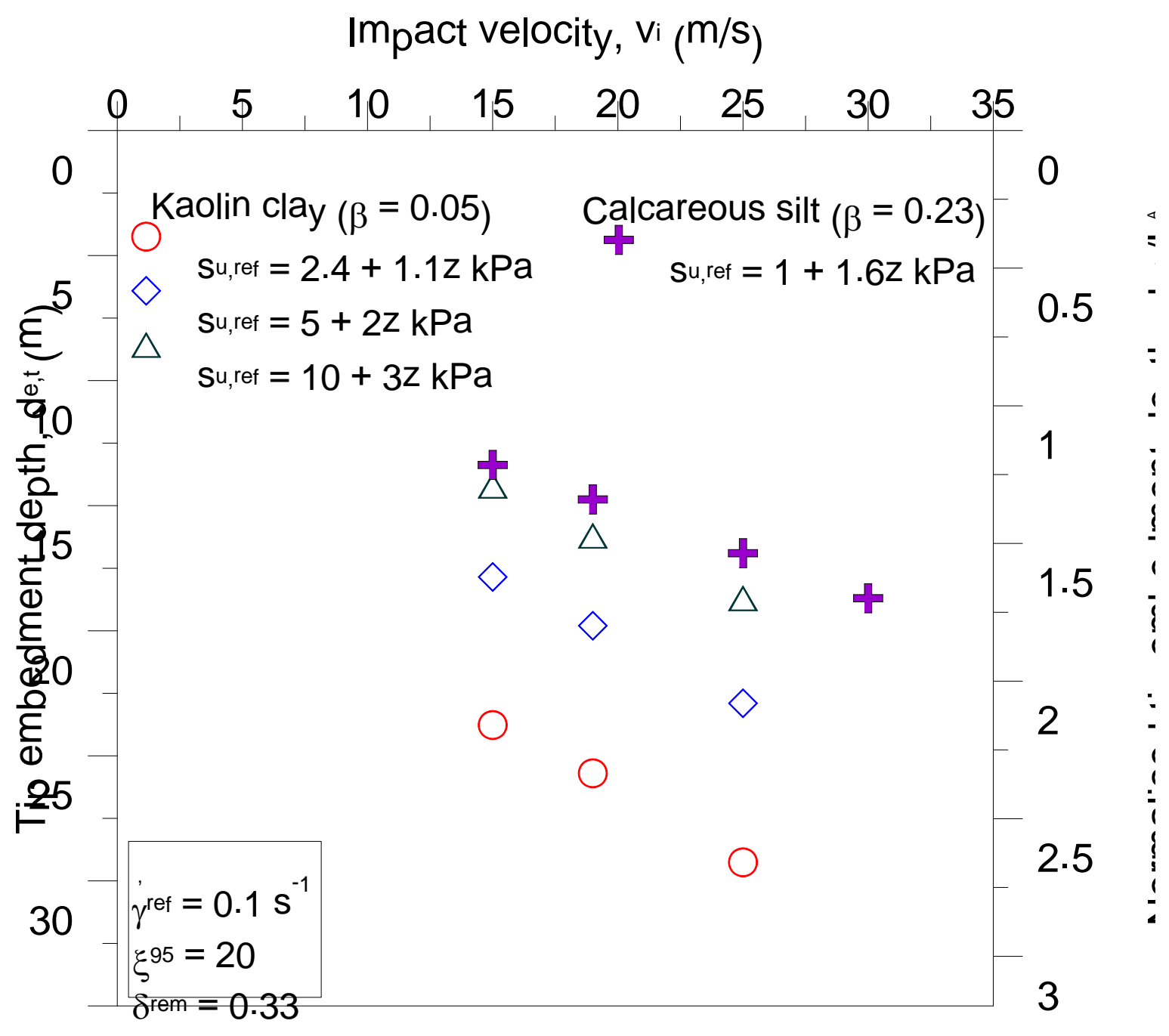

Figure 6. Effect of various factors on anchor tip embedment depth (Groups I and II,

Table 2) 

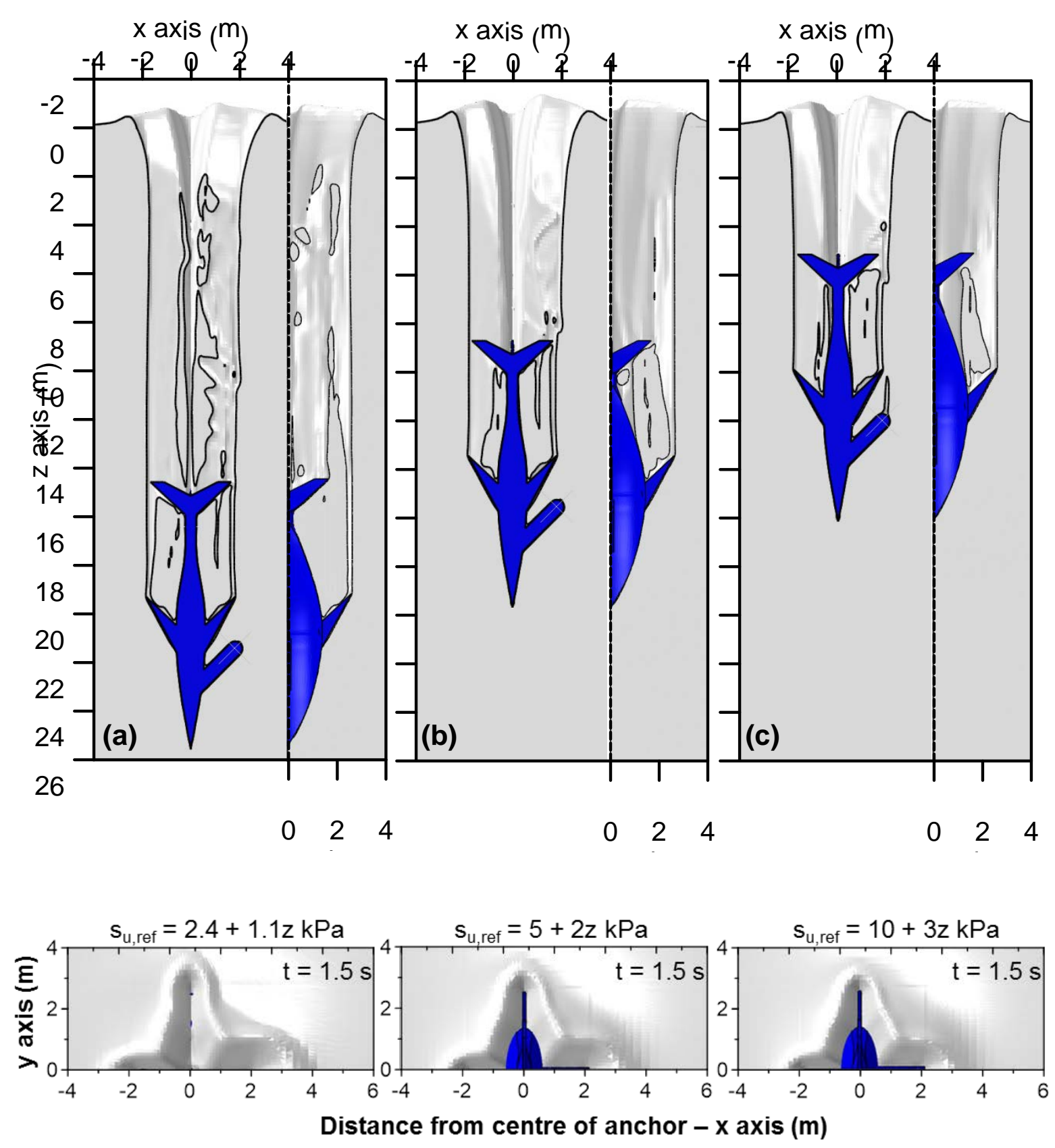

(d) Plan view

Figure 7. Effect of soil strength on cavity condition above installed anchor (anchor F3; in Group I, Table 2): (a) $\mathrm{s}_{\mathrm{u}, \mathrm{ref}}=2.4+1.1 \mathrm{z} \mathrm{kPa}$; (b) $\mathrm{s}_{\mathrm{u}, \mathrm{ref}}=5+2 \mathrm{z} \mathrm{kPa}$; (c) $\mathrm{s}_{\mathrm{u}, \mathrm{ref}}=10+3 \mathrm{z}$ kPa; (d) Plan view 


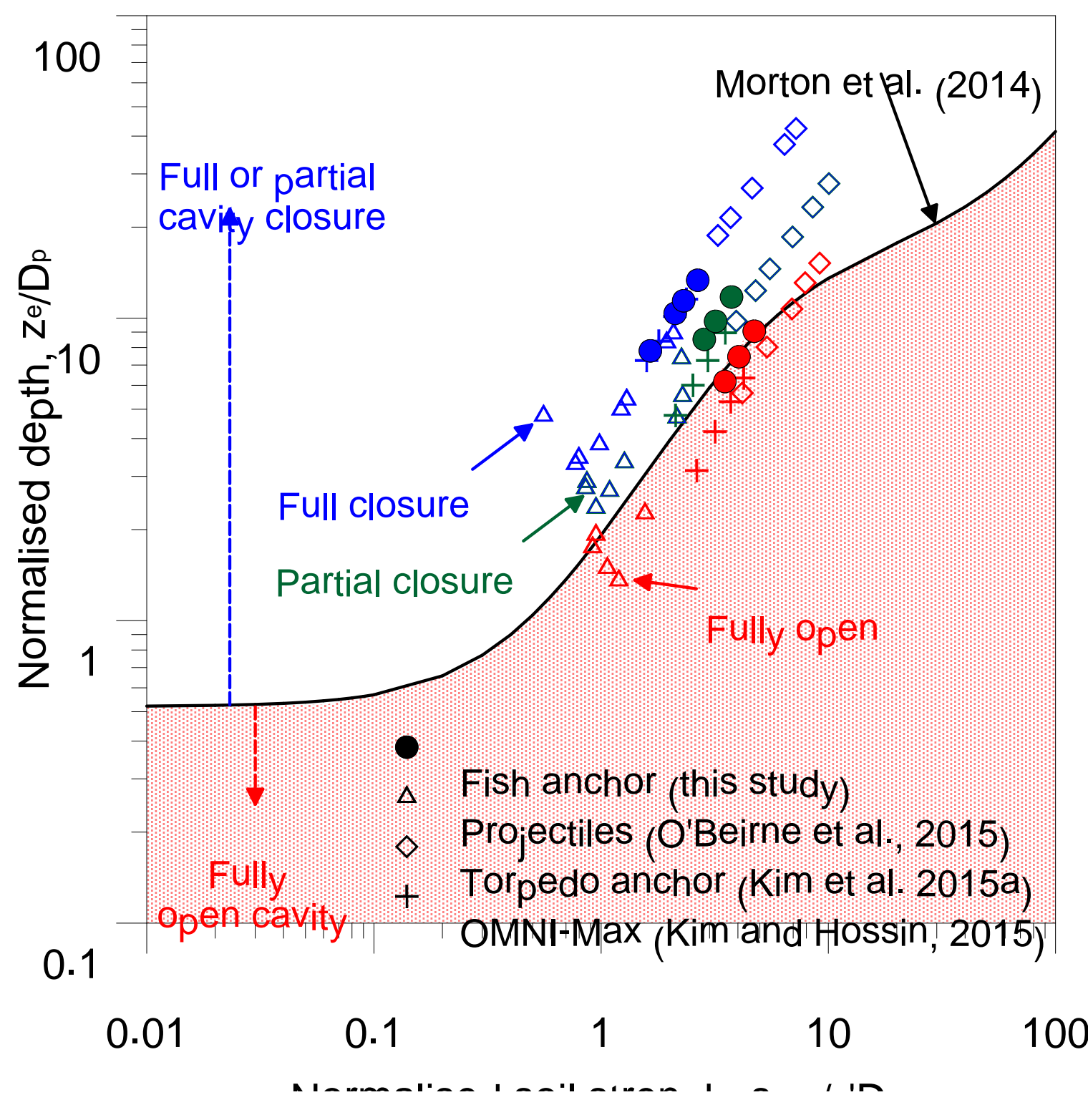

Figure 8. Correlation diagram with cavity condition, penetration depth and soil strength 


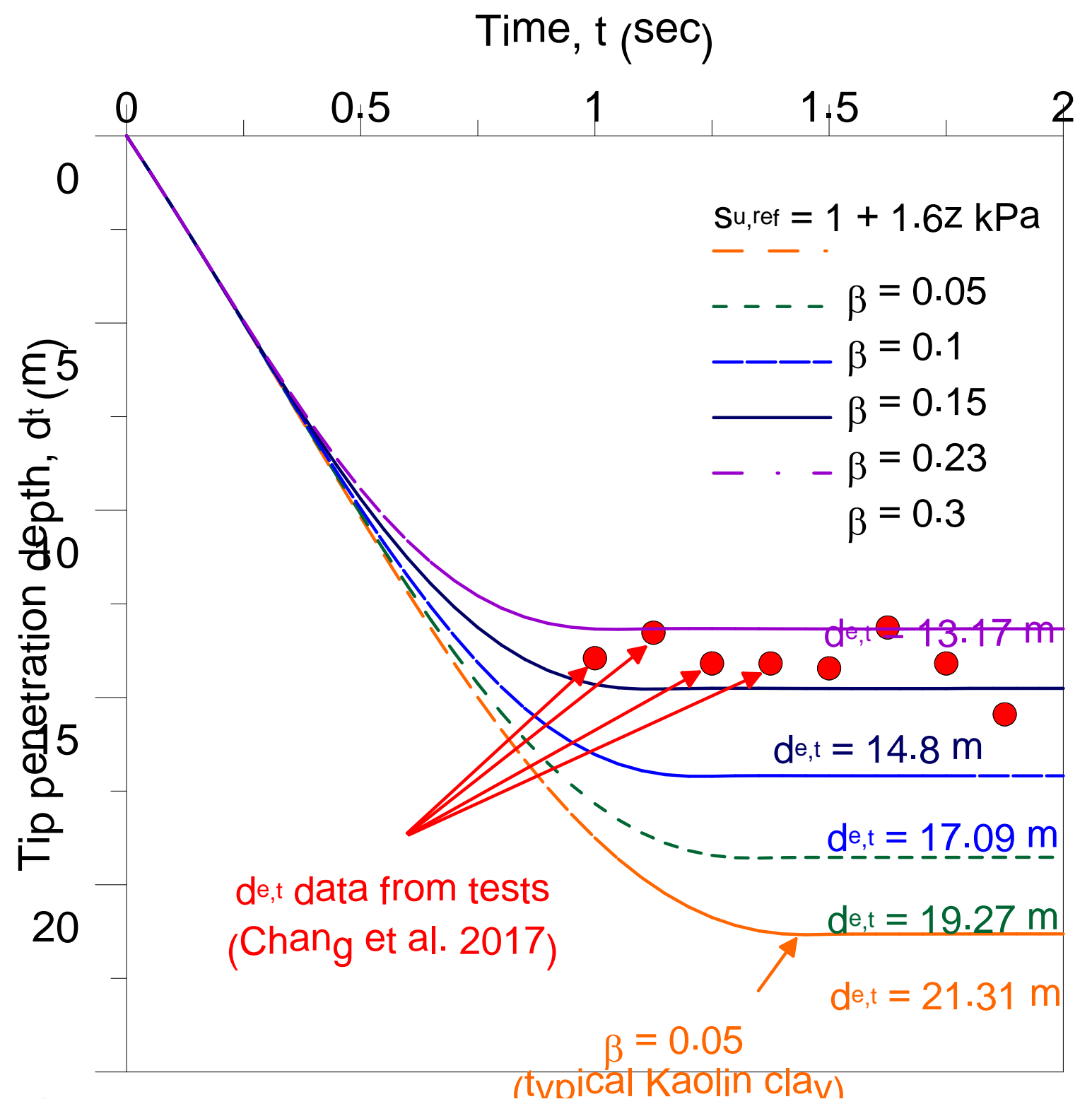

Figure 9. Effect of rate parameter on the embedment depth in calcareous silt (anchor F4; in Group II, Table 2) 


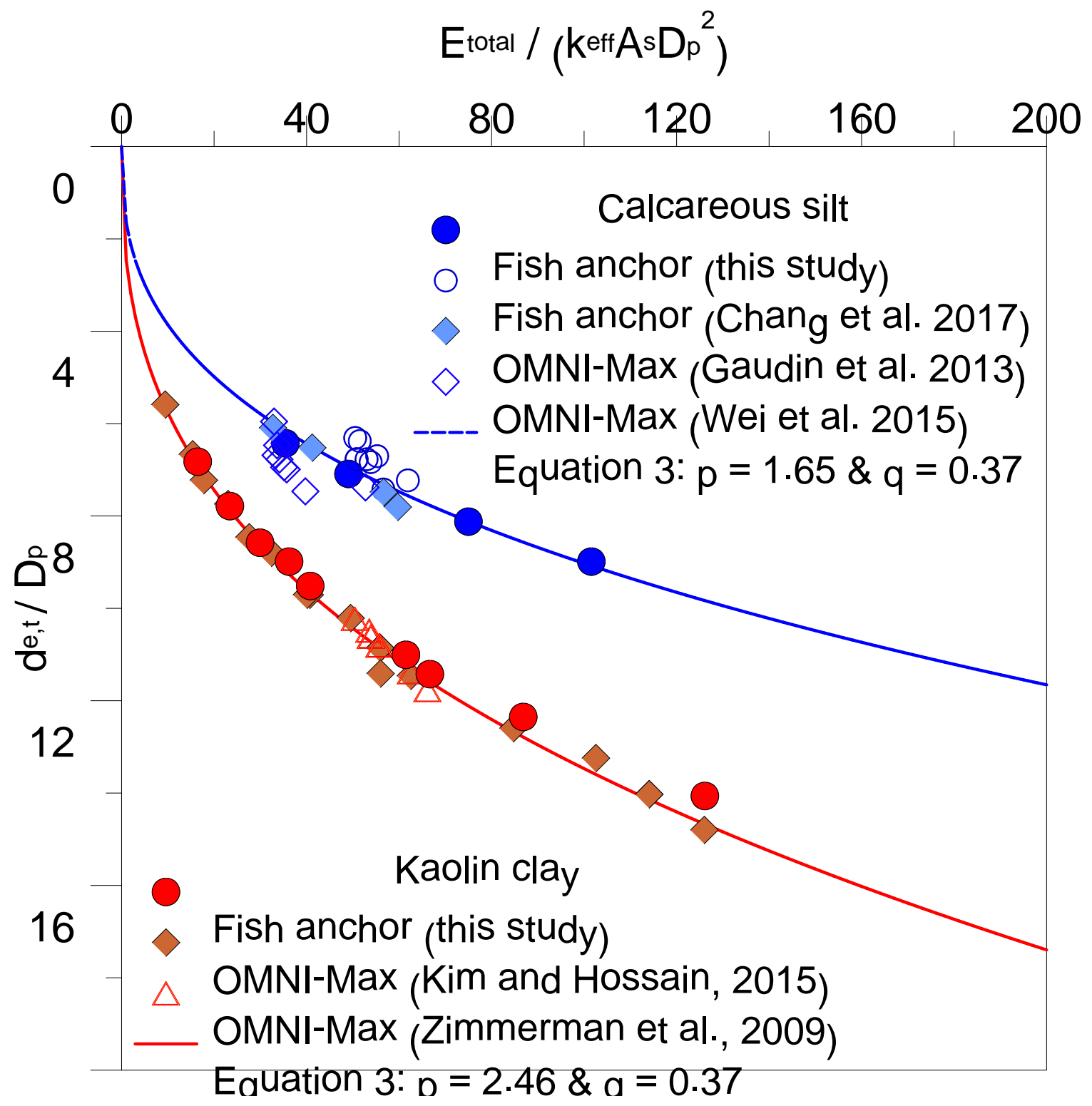

Figure 10. Modified energy method for assessing anchor embedment depths in clay and silt (Groups I and II, Table 2) 


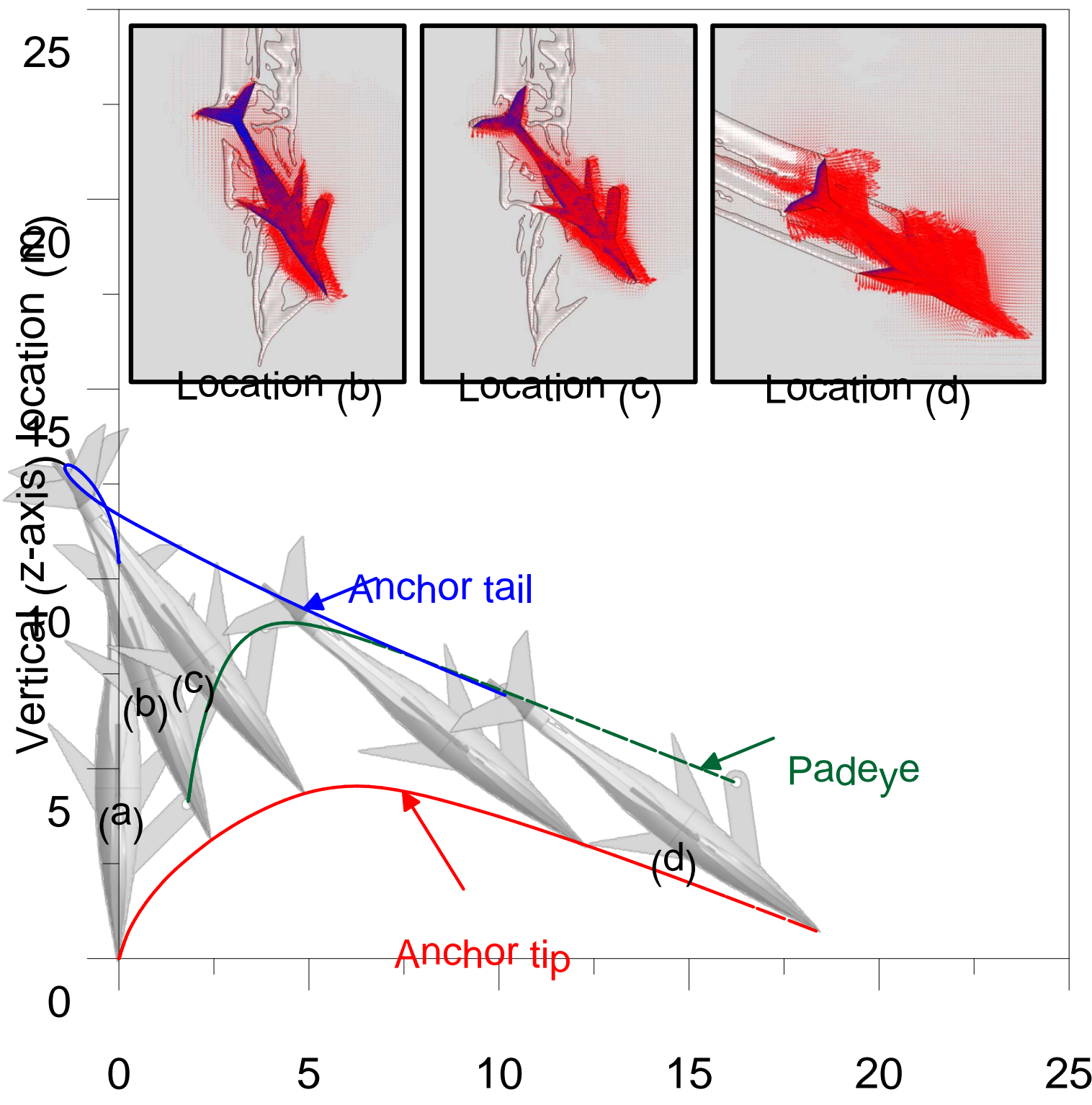

Figure 11.Typical fish anchor diving trajectories and corresponding failure mechanisms (in Group III, Table 2): (a) Before pulling out; (b) Keying; (c) Transition of diving; (d) Diving 


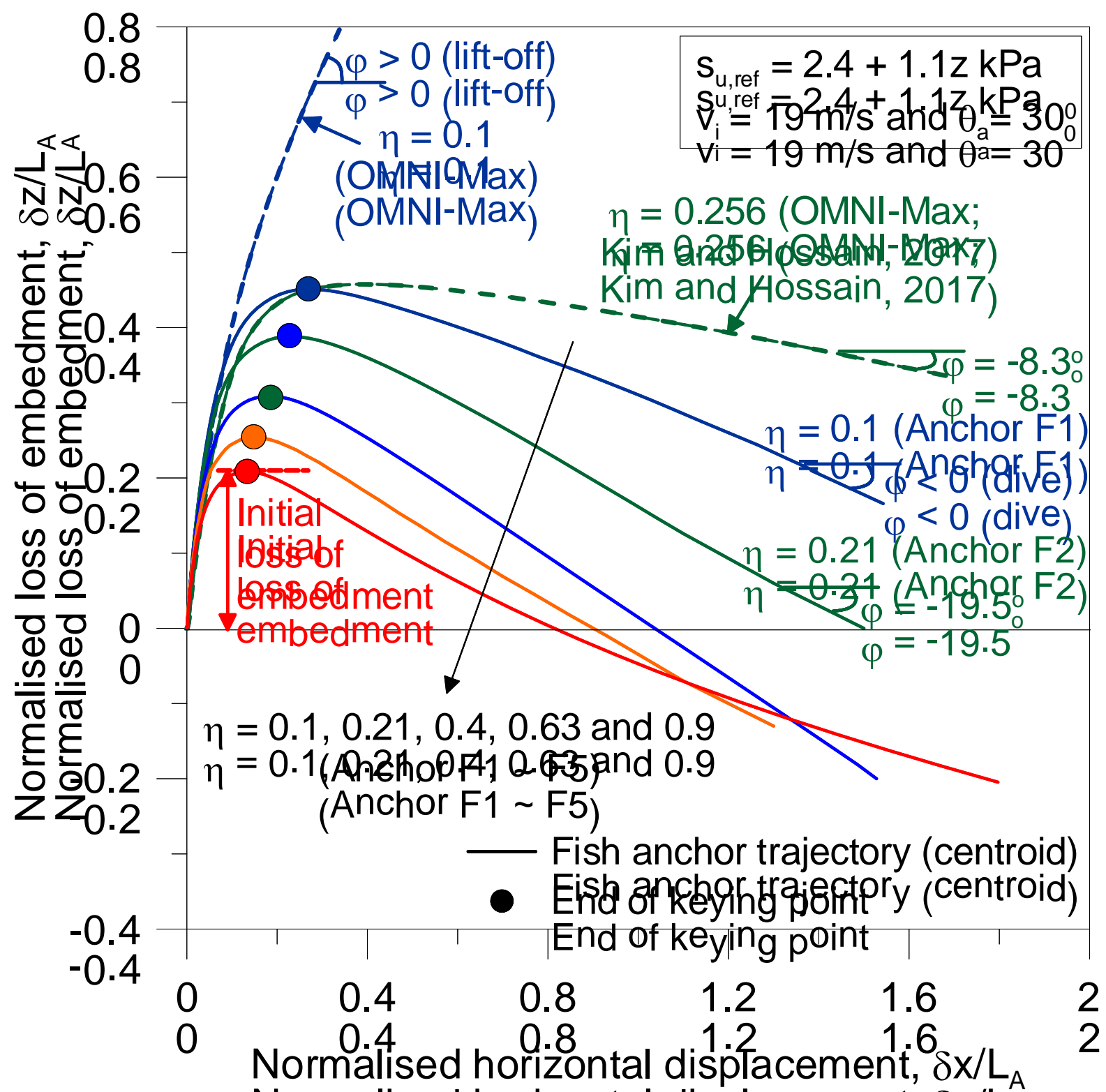

(a) Anchor trajectories at centroid 


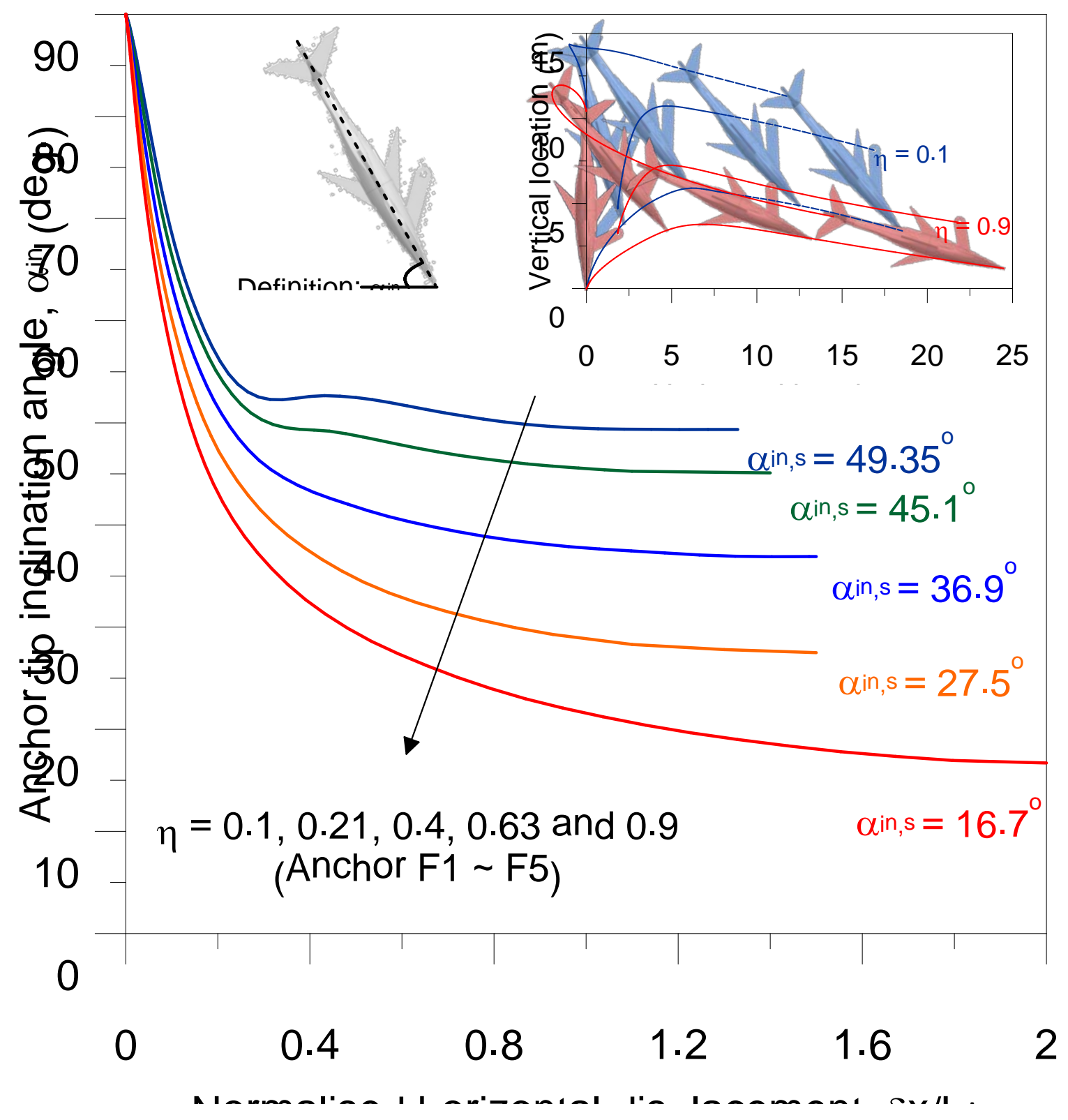

(b) Inclined angles at anchor tip

Figure 12. Effect of padeye offset ratio (Group III, Table 2): (a) Anchor trajectories at centroid; (b) Inclined angles at anchor tip 


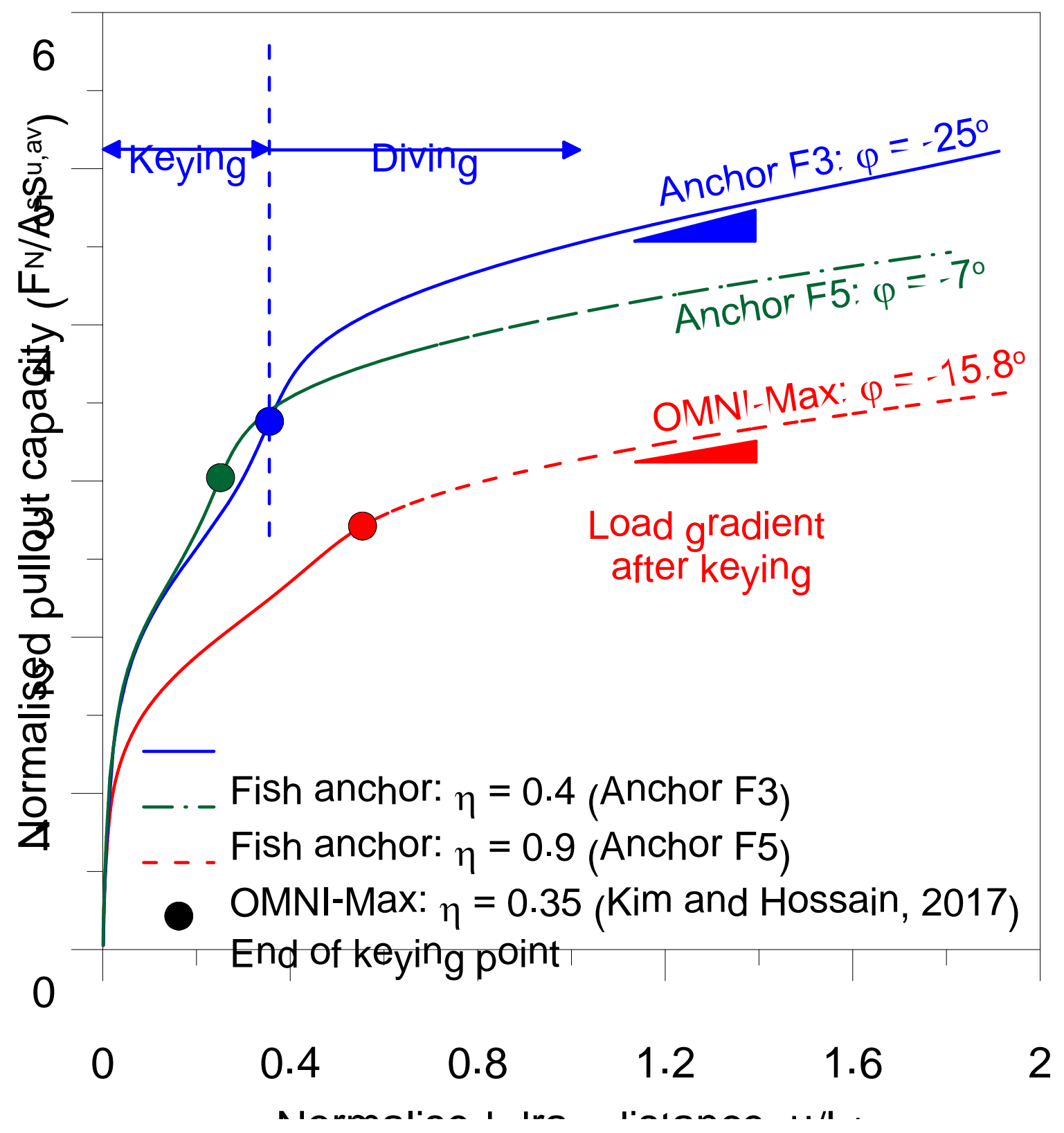

Figure 13. Comparisons of pullout resistance-drag distance profiles (in Group III, Table 2) 


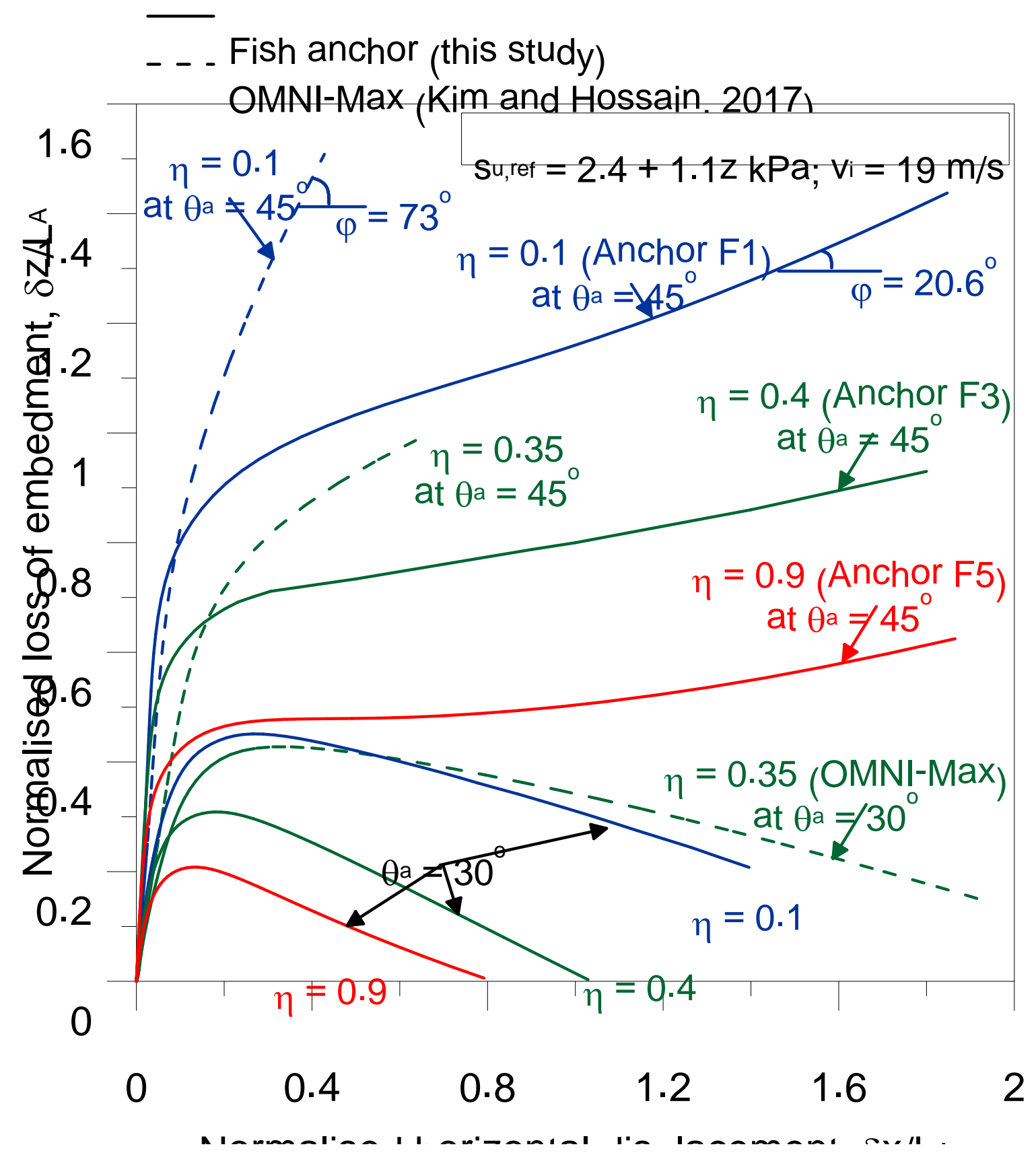

Figure 14. Effect of pullout angle on anchor trajectories (Groups III and IV, Table 2) 


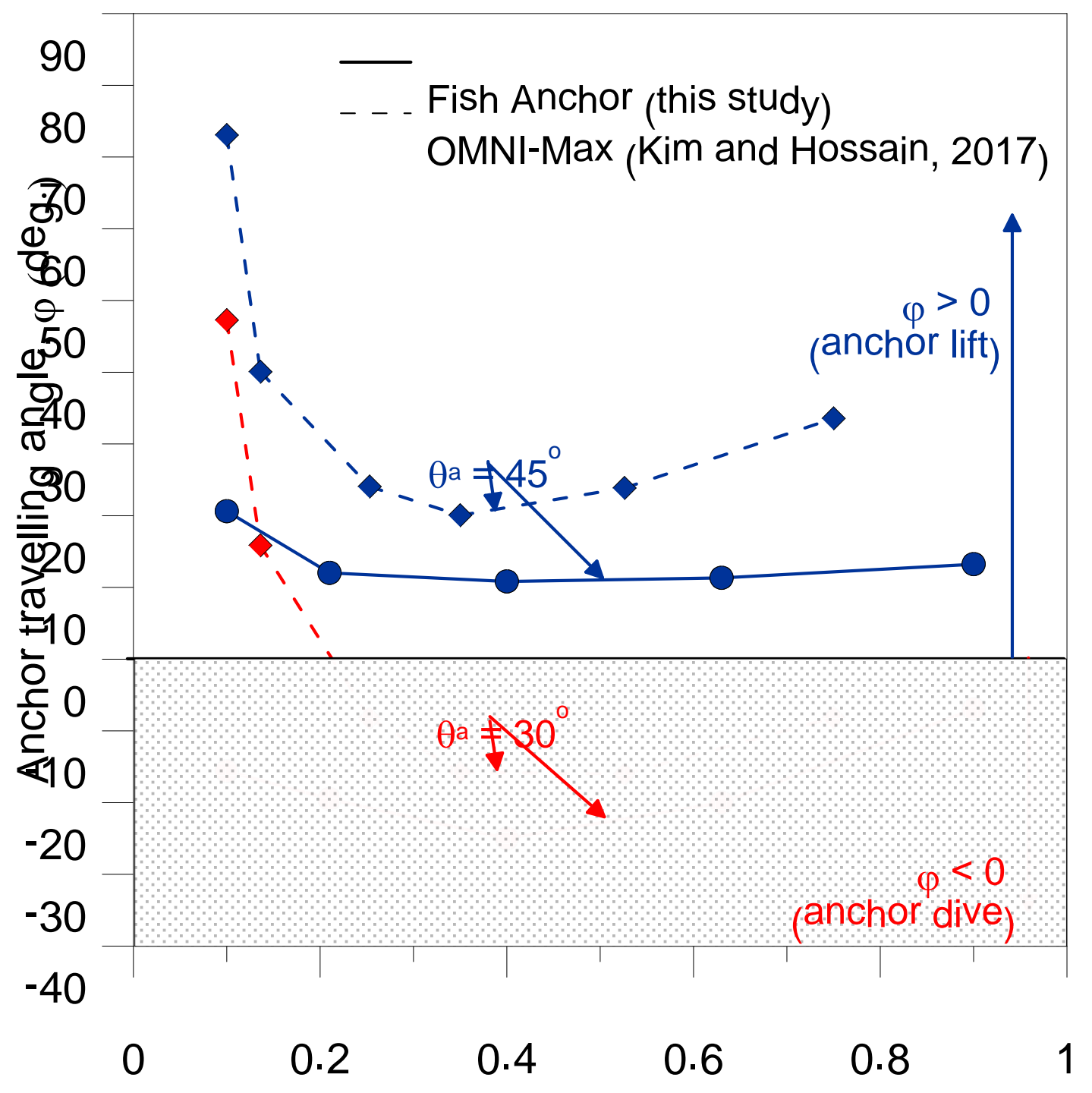

Figure 15. Design chart for anchor travelling angle as a function of padeye offset ratio and load inclination at padeye (Groups III and IV, Table 2) 


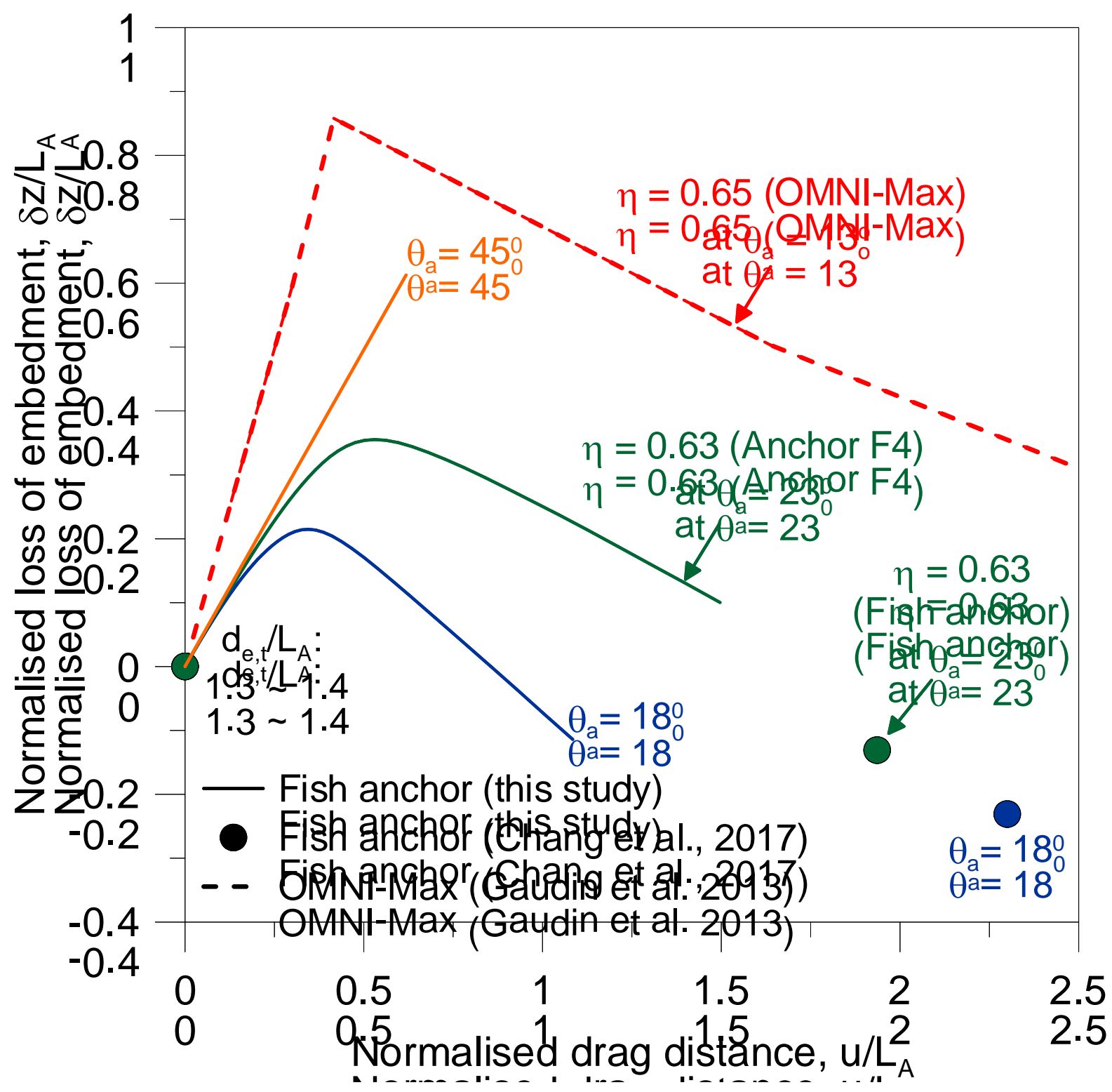

Figure 16. Pullout behaviour in calcareous silt (Groups V, Table 2) 


\section{NOMENCLATURE}

$\mathrm{A}_{\mathrm{p}} \quad$ anchor frontal projected area

$\mathrm{A}_{\mathrm{s}} \quad$ embedded anchor total surface area

$\mathrm{C}_{\mathrm{d}} \quad$ drag coefficient

$\mathrm{D}_{\mathrm{p}} \quad$ anchor frontal projected area equivalent diameter (including fins and padeye)

$\mathrm{d}_{\mathrm{e}, \mathrm{t}} \quad$ anchor tip embedment (final penetration) depth

$d_{t} \quad$ anchor tip penetration depth

$E_{\text {total }}$ total energy during anchor penetration

$\mathrm{e}_{\mathrm{n}} \quad$ padeye offset distance

$\mathrm{e}_{\mathrm{p}} \quad$ padeye eccentricity

F pullout resistance

$\mathrm{F}_{\mathrm{N}} \quad$ net pullout capacity

g Earth’s gravitational acceleration

k shear strength gradient with depth

$k_{\text {eff }} \quad$ effective soil strength gradient

$\mathrm{L}_{\mathrm{A}} \quad$ anchor shaft length

m dry mass of anchor

$\mathrm{m}^{\prime} \quad$ effective mass of the anchor (submerged in soil) 
r, q exponents and coefficient of energy models

$\mathrm{S}_{\mathrm{t}} \quad$ soil sensitivity

$\mathrm{s}_{\mathrm{u}} \quad$ undrained shear strength

$\mathrm{s}_{\mathrm{u}, \mathrm{av}} \quad$ average undrained shear strength over the anchor shaft length

$\mathrm{s}_{\mathrm{u}, \mathrm{ref}} \quad$ reference undrained shear strength

$\mathrm{s}_{\mathrm{u}, \mathrm{ze}} \quad$ soil strength at depth of the widest part of penetrating object

t time after anchor tip impacting seabed

$t_{F} \quad$ fin thickness

u drag distance

V anchor penetrating velocity

$\mathrm{v}_{\mathrm{i}} \quad$ anchor impact velocity

$\mathrm{V}_{\mathrm{A}}$ anchor volume

$\mathrm{W}_{\mathrm{d}}$ anchor dry weight

$\mathrm{W}_{\mathrm{s}}$ anchor submerged weight in water

$\mathrm{W}_{\mathrm{ss}} \quad$ anchor submerged weight in soil

z depth below soil surface

$\mathrm{z}_{\mathrm{e}} \quad$ depth of the widest part of penetrating object

$\alpha_{\text {in }} \quad$ anchor tip inclination angle

$\alpha_{\text {in,s }} \quad$ stabilised anchor tip inclination angle 
$\beta \quad$ rate parameter for power expression

$\delta_{\text {rem }} \quad$ remoulded strength ratio

$\delta \mathrm{x} \quad$ horizontal displacement

$\delta z \quad$ loss of embedment depth

$\gamma^{\prime} \quad$ effective unit weight of soil

\& shear strain rate

$\&_{\text {ref }} \quad$ reference shear strain rate

$\eta \quad$ padeye offset ratio

$\varphi \quad$ anchor travelling angle

$\mu \quad$ rate parameter for logarithmic expression

$\theta_{\mathrm{a}} \quad$ pullout angle at the padeye

$\tau_{\max } \quad$ limiting shear strength at soil-anchor interface

$\omega \quad$ padeye offset angle

$\xi \quad$ cumulative plastic shear strain

$\xi_{95}$ cumulative plastic shear strain required for $95 \%$ remoulding 